\title{
CONFIGURACIÓN DEL PODER DE DIRECCIÓN DEL EMPLEADOR: DENOMINACIÓN, NATURALEZA JURÍDICA, FUNDAMENTO Y CONTENIDO
}

\author{
CONFIGURATION OF EMPLOYER'S MANAGEMENT POWER: \\ DENOMINATION, LEGAL NATURE, FOUNDATION AND \\ CONTENT
}

RAÚL FERNÁNDEZ TOLEDO***

\section{RESUMEN}

El presente trabajo tiene por propósito efectuar una construcción dogmática del poder de dirección del empleador conforme al ordenamiento jurídico chileno, determinándose cuál es su correcta denominación, su fundamento y naturaleza jurídica y, finalmente, su contenido. Todos aspectos del poder de dirección que, de una u otra forma, son discutidos en Chile, debido a que no existe una opinión unánime acerca de los mismos en la doctrina y jurisprudencia, ni tampoco una regulación exhaustiva por parte del legislador.

Palabras claves: Poder de dirección, naturaleza jurídica, denominación, contenido.

\footnotetext{
* Abogado, Licenciado en Ciencias Jurídicas y Sociales por la Universidad de Concepción. Magíster en Derecho del Trabajo y de la Seguridad Social por la Universidad de Talca y la Universidad de Valencia. Profesor Asistente del Departamento de Derecho del Trabajo y de la Seguridad Social, Facultad de Derecho de la Universidad de Chile. Dirección postal: Facultad de Derecho, Universidad de Chile, Avenida Santa María Nº636, Providencia, Chile. Correo electrónico rfernandez@derecho.uchile.cl. ** Los dictámenes y ordinarios citados en el presente trabajo han sido pronunciados por la Dirección del Trabajo.

Artículo recibido el 11 de marzo de 2019 y aceptado para su publicación el 5 de junio de 2019 .
} 


\section{ABSTRACT}

The purpose of this paper is to make a dogmatic construction of the employer's power of management in accordance with the Chilean legal system, determining what is its correct denomination, its foundation and legal nature and, finally, its content. All aspects of the power of management that, in one way or another, are subject of debate in Chile because there is no unanimous opinion about them in the doctrine and jurisprudence or an exhaustive regulation by the national legislator either.

Keywords: power of management, legal nature, denomination, content.

\section{INTRODUCCIÓN}

El contrato de trabajo tiene ciertas particularidades que no existen en otro contrato de prestación de servicios personales, que derivan fundamentalmente de la ejecución subordinada continuada -a tracto sucesivo- de los servicios por parte del trabajador. Para lograr la función económica del negocio laboral le es reconocido a la parte acreedora ciertos derechos subjetivos que se ejercen sobre el dependiente, llamados comúnmente "poderes", ${ }^{1}$ los que no pueden ser renunciados, modificados ni delegados -salvo por disposición legal- en terceras personas, ${ }^{2}$ por pertenecerles exclusivamente en su calidad

\footnotetext{
1 Cester, Carlo; Mattarolo, Maria, Diligenza e obbedienza del prestatore di lavoro. Art. 2014, Giuffrè Editore, Milano, 2007, pp. 285-289; FerRAnTe, Vincenzo, Direzione e gerarchia nell'impresa (e nel lavoro pubblico privatizzato). Art. 2086, Giuffrè Editore, Milano, 2012, pp. 26-31.

2 Véase similar opinión en la doctrina comparada: Montoya Melgar, Alfredo, "El poder de dirección del empresario en las estructuras empresariales complejas", Revista del Ministerio del Trabajo y Asuntos Sociales, 2004, N48, pp. 135-145; Cruz Villalón, Jesús, "Poder de dirección y nuevas estructuras empresariales", en: Escudero, R. (Coord.), El poder de dirección del empresario: nuevas perspectivas, La Ley, Madrid, 2005, p. 224; Bejarano HernÁndez, Andrés, "Irrenunciabilidad del poder de dirección del empresario y límites convencionales al mismo", Revista Española de Derecho del Trabajo, 2010, No147, pp. 641-643; Montoya Melgar, Alfredo, "Libertad de empresa y poder de dirección del empresario en las relaciones laborales” en: Sánchez, C.; González, F. (Coords.), Libertad de empresa y poder de dirección del empresario en las relaciones laborales, Aranzadi - Thomson Reuters, Navarra, 2011, p. 32. En el derecho chileno el Código del Trabajo, en el artículo 183-X, a propósito del trabajo de servicios transitorios, delega el poder de dirección en la empresa usuaria durante el tiempo que el trabajador de servicios transitorios le presta servicios.
} 
de empleador, ${ }^{3}$ formando parte del orden público laboral, ${ }^{4}$ sin perjuicio del control estatal de la legalidad de su ejercicio. Uno de esos derechos es el conocido comúnmente como poder de dirección, cuyo núcleo esencial está constituido por las facultades del empleador de impartir órdenes e instrucciones al trabajador dependiente para lograr la correcta ejecución de la prestación debida y mantener la disciplina al interior de la empresa. Poder que, tiene como contrapartida el deber de obediencia del dependiente, en virtud del cual debe cumplir las órdenes e instrucciones impartidas por su empleador. Es por ello que se dice que el poder de dirección y el deber de obediencia son dos caras de una misma moneda, ${ }^{5}$ que derivan del trabajo subordinado, donde uno manda y otro obedece. Ambos forman parte de una misma realidad, expresión de la subordinación, no siendo posible la subsistencia de uno de ellos prescindiendo del otro. ${ }^{6}$

Si bien existe claridad en la doctrina y jurisprudencia sobre cuál es el contenido esencial del poder de dirección, hay una serie de aspectos del mismo en que existe una disparidad de opiniones, lo que se debe principalmente a la nula o, más bien, escasa regulación del mismo que existe en la legislación laboral, siendo su configuración eminentemente doctrinal y jurisprudencial, complementada con algunas normas constitucionales, legales y reglamentarias. En efecto, no existe una opinión unánime sobre su denominación y naturaleza jurídica -ambos aspectos conectados- al

\footnotetext{
3 Dirección del Trabajo, ordinario Nº1165, 20 de marzo de 2013; Dirección del Trabajo, ordinario Nº726, 7 de febrero de 2018. En similares términos: Primer Juzgado de Letras del Trabajo de Santiago, 11 de enero de 2017, RIT O-4982-2016; Juzgado de Letras y del Trabajo de Victoria, 11 de octubre de 2018, RIT O-72018. Se ha indicado: "es el empleador, parte del contrato, el único titular de los poderes directivos. Por tanto, es él el único facultado para ejercer los poderes inherentes a la posición de subordinación jurídica en que se encuentra el trabajador. Titularidad y ejercicio del poder de dirección en la concepción clásica van estrechamente vinculados, de modo que no se concibe la posibilidad que se produzca una escisión entre la titularidad y ejercicio de los poderes directivos", cfr.: CRUz, cit. (n. 2), p. 224.

4 Inclusive, los poderes del empleador no pueden ser objeto de negociación colectiva, tal como lo indica el artículo 306 inciso $4^{\circ}$ del Código del Trabajo.

5 Román de la Torre, María Dolores, Poder de dirección y contrato de trabajo, Ediciones Grapheus, Valladolid, 1992, p. 349; Cester y Mattarolo, cit. (n. 1), pp. 276-279; Morato García, Rosa María, Derecho de resistencia y ejercicio irregular del poder de dirección, Editorial Comares, Granada, 2011, p. 59 ss.; BEJARANO, cit. (n. 2), p. 644. Se ha señalado que el poder del empleador de impartir órdenes y esperar que las mismas sean obedecidas por el trabajador son características inherentes a todo contrato de trabajo. En particular, el trabajador es obligado a cumplir con toda legal y razonable instrucción otorgada por un supervisor o gerente del empleador, cfr.: STEWART, Andrew; Forsyth, Anthony; IRVING, Mark; Johnstone, Richard; Mccrystal, Shae, Creighton \& Stewart's labour law, The Federation Press, Sydney, 2016, sixth edition, p. 496; STEWART, Andrew, Stewart's guide to employment law, The Federation Press, Sydney, 2018, sixth edition, p. 281.
}

6 Morato, cit. (n. 5), p. 17. 
punto que se le denomina indistintamente potestad o poder de mando o de dirección. En el presente trabajo se demostrará que no es propiamente una potestad, sino un poder; esto es, un derecho subjetivo potestativo, que se ejerce o manifiesta a través de un conjunto de facultades.

Otra cuestión que debe resolverse es determinar el fundamento del poder de dirección. Debe dilucidarse si su justificación solamente está en la Constitución Política; en concreto en los derechos fundamentales de libertad de empresa y derecho de propiedad de que está dotado el empleador, o también, en el contrato de trabajo, por ser una expresión de la subordinación o dependencia y, por tanto, un elemento esencial del contrato de trabajo.

Estrechamente conectado con la discusión anterior, se encuentra el contenido del poder de dirección, siendo uno de los aspectos del mismo donde existe un mayor número de opiniones dispares. Existe una posición amplia que sostiene que forman parte del poder de dirección el poder disciplinario, el ius variandi, la facultad de control y el poder de reglamentación, es decir, que todos los poderes del empleador forman parte del contenido del poder de dirección. En cambio, existe una segunda posición que distingue cada unos de los poderes del empleador, los que para nosotros son los siguientes: poder de dirección, poder disciplinario, ius variandi y poder de control, los cuales, si bien están estrechamente conectados, por constituir instrumentos dirigidos a que el contrato de trabajo cumpla su función económica, velando porque se ejecute correctamente la prestación de trabajo con respeto a la disciplina laboral interna, tienen un contenido y fundamento jurídico distinto. A estos poderes se agregan las facultades administrativas y organizativas laborales, que tienen influencia en la constitución y extinción del contrato de trabajo.

Para solucionar cada uno de los problemas jurídicos indicados se recurre a la doctrina y jurisprudencia judicial y administrativa nacional. La doctrina extranjera se utiliza como argumento de refuerzo, especialmente la española, italiana y francesa.

\section{DENOMINACIÓN Y NATURALEZA JURÍDICA DEL PODER DE DIRECCIÓN}

El poder de dirección no tiene una denominación unívoca en nuestro medio. Es así que, la jurisprudencia administrativa ${ }^{7}$ y un sector de la

\footnotetext{
7 Dirección del Trabajo, dictamen N4589/260, 4 de agosto de 1997; Dirección del Trabajo, dictamen N5845/365, 30 de noviembre de 1999; Dirección del Trabajo, dictamen N²376/65, 2 de junio de
} 
doctrina nacional lo denomina, además, "poder de mando", "potestad de mando" o simplemente "potestad de dirección". ${ }^{9}$ Lo mismo ocurre con un sector de la jurisprudencia judicial. ${ }^{10}$ Inclusive, es posible observar que este sector emplea como sinónimas las palabras poder y potestad. Así las cosas, frecuentemente se utilizan indistintamente las expresiones "potestad de mando" o "potestad de dirección" "11 para aludir al poder de dirección.

Referirse al poder de dirección como una potestad es cuestionable por dos razones, principalmente. En primer término, calificarlo como potestad contravendría su propia naturaleza jurídica de derecho subjetivo del empleador y su objetivo. El mismo tiene como propósito la satisfacción de los propios intereses del empleador, siendo ese su objetivo principal, en cambio, las potestades son atribuidas a un sujeto para la satisfacción de intereses que no son los propios sino los de terceras personas, ${ }^{12}$ siendo comunes en las relaciones existentes entre Estado y ciudadano, ${ }^{13}$ en que el Estado está el servicio de la persona. De este modo, si se acepta que el poder de dirección realmente es una potestad del empleador, importa afirmar que él mismo busca la consecución de un interés o un bien distinto

2005; Dirección del Trabajo, dictamen $\mathrm{N}^{\circ} 2210 / 035,5$ de junio de 2009; Dirección del Trabajo, ordinario $\mathrm{N}^{\circ} 1265,4$ de marzo de 2016.

8 Ugarte Cataldo, José Luis, "El contenido del contrato individual de trabajo", Boletín Oficial de la Dirección del Trabajo, noviembre 1996, N94/96, pp. 9-12; Lanata FuenZALIDA, Gabriela, Contrato Individual de Trabajo, LegalPublishing, Santiago, 2010, 4ª ed. Actualizada, p. 123; Gamonal Contreras, Sergio; Guidi Moggia, Caterina, Manual del Contrato de Trabajo, LegalPublishing, Santiago, 2012, $3^{\text {a }}$ ed. Revisada y Actualizada, pp. 87-91.

9 Lizama Portal, Luis; Lizama Castro, Diego, Manual de Derecho Individual del Trabajo, Ediciones DER, Santiago, 2019, pp. 113-114. En similares términos: Lizama Portal, Luis, "Fernández Toledo, Raúl, El poder disciplinario del empleador", Revista Chilena de Derecho del Trabajo y de la Seguridad Social, 2016, Vol. 7, ํ13, p. 202.

${ }^{10}$ Corte de Apelaciones de Copiapó, 17 de octubre de 2016, Rol N82-2016; Corte de Apelaciones de Valparaíso, 29 de mayo de 2018, Rol N²37-2018.

${ }^{11}$ Dirección del Trabajo, dictamen N³351/0185, 9 de junio de 1997; Dirección del Trabajo, ordinario N5030, 26 de octubre de 2017; Gamonal y Guidi, cit. (n. 8), pp. 90-91. La excepción la constituyen ciertos autores que solamente utilizan la expresión "potestad" para hacer referencia a los poderes del empleador: LizAma, cit. (n. 9), p. 202; LizAma y LizAma, cit. (n. 9), pp. 113-114.

${ }^{12}$ Carnelutti, Francesco, Teoria generale del Diritto, Foro Italiano, Roma, 1940, p. 219; Romano, Santi, Fragmentos de un diccionario jurídico (trad. S. Sentís M. y M. Ayerra R.), EJEA, Buenos Aires, 1964, p. 309; De Castro y Bravo, Federico, Derecho Civil de España, Instituto de Estudios Políticos, Madrid, 1984, p. 571 ss.; Poquet Catalá, Raquel, El actual poder de dirección y control del empresario, Thomson Reuters-Aranzadi, Pamplona, 2013, p. 26; Román, cit. (n. 5), p. 115.

${ }^{13}$ RUAY SÁEz, Francisco Alberto, "El poder disciplinario del empleador, por Raúl Fernández Toledo. Una reseña", Revista Internacional y Comparada de Relaciones Laborales y Derecho del Empleo, 2017, Vol. 5, N³, p. 266. 
al proyecto empresarial perseguido por el empleador a través de su actividad productiva. Sin embargo, ello no resulta ser efectivo, debido a que el poder de dirección es un instrumento conferido al acreedor del trabajo subordinado que contribuye a la obtención del fin económico o social perseguido por el empleador. No es un fin en sí mismo sino un medio para que se lleve a cabo correctamente la actividad empresarial mediante la gestión de las relaciones laborales que se desenvuelven en su interior. ${ }^{14}$

En segundo lugar, la potestad no se genera en relación jurídica alguna, ni en negocios jurídicos, sino que procede directamente del ordenamiento jurídico, ${ }^{15}$ en cambio, el poder de dirección tiene su fundamento y presupuesto de ejercicio en el contrato de trabajo. "A la potestad no corresponde ningún deber, positivo o negativo, sino una simple sujeción o sometimiento de otros sujetos a soportar sobre su esfera los eventuales efectos derivados del ejercicio de la potestad"; ${ }^{16}$ por el contrario, el poder de dirección tiene como correlativo el deber de obediencia del trabajador, no existiendo sin éste, siendo ambas expresiones de la subordinación. ${ }^{17}$

Conforme a lo expuesto, ni siquiera siguiendo la concepción de HoHFELD ${ }^{18}$ sobre derechos subjetivos y potestades -que es utilizada por parte de la doctrina naciona $1{ }^{19}$ para indicar que el poder de dirección es una potestad-se puede afirmar que tiene esta calidad, desde que su ejercicio activa el deber de obediencia del dependiente, debiendo en virtud del mismo acatar las disposiciones impartidas por el empleador, lo que claramente no una simple sujeción.

\footnotetext{
${ }^{14}$ Morato, cit. (n. 5), p. 36. El poder de dirección es una herramienta esencial de la empresa moderna. El mismo permite al empleador llevar a cabo su actividad debidamente y responder oportunamente a las circunstancias que no pudieron ser previstas al momento de celebrarse el contrato de trabajo. En otras palabras, este poder otorga al empleador la posibilidad de impartir órdenes sin la necesidad de solicitar previamente autorización al trabajador, cfr.: De Stefano, Valerio, "Negotiating the algorithm: automation, artificial intelligence and labour protection", Employment Working Paper, International Labour Office, 2018, N²46, p. 14.

${ }^{15}$ García de Enterría, Eduardo; Fernández, Tomás - Ramón, Curso de Derecho Administrativo, Civitas - Thomson Reuters, Madrid, 2015, decimoséptima edición, T I, p. 482.

${ }^{16}$ García y Fernández, cit. (n. 15), p. 482.

${ }^{17}$ Román, cit. (n. 5), pp. 75 y 349; Cester y Mattarolo, cit. (n. 1), pp. 276-279; Morato, cit. (n. 5), p. 59 ss.; Bejarano, cit. (n. 2), p. 644; Corte de Apelaciones de Santiago, 29 de marzo de 2019, Rol $\mathrm{N}^{\circ} 2555-2018$.

${ }^{18}$ Hohfeld, Wesley, Conceptos jurídicos fundamentales, (trad. G. Carrió), Distribuciones Fontamara, Ciudad de México, 1995, $3^{\text {a }}$ ed., p. 45 ss.; Arriagada, María Beatriz, "El concepto Hohfeldiano de derecho subjetivo", Revista de Ciencias Sociales, 2014, Nº5, pp. 13-43; ArriagAdA, María Beatriz, "Conceptos jurídicos de derechos subjetivos", Eunomía. Revista en Cultura de la Legalidad, oct. 2016- mar 2017, $\mathrm{N}^{\circ} 13$, pp. 152-162.

${ }^{19}$ Gamonal y Guidi, cit. (n. 8), pp. 87-91; Lizama y Lizama, cit. (n. 9), pp. 113-114.
} 
La negativa a calificar el poder de dirección como potestad ha sido aceptada por la doctrina comparada. ${ }^{20}$ Ahora, la duda que surge dice relación con cuál es la naturaleza jurídica de este poder, si una facultad o derecho subjetivo. Si bien existe una estrecha conexión entre derecho subjetivo y facultad empleándose, en ocasiones, como sinónimos, la realidad de las cosas es que son diferentes, operando una dualidad de continente a contenido entre ambos, en que el derecho subjetivo es la categoría general que abarca, que comprende, ciertas facultades que permiten hacer efectivo dicho derecho, siendo éstas simples manifestaciones concretas del mismo. ${ }^{21} \mathrm{El}$ poder directivo ha sido calificado de derecho subjetivo, ${ }^{22}$ que se ejecuta a través de diversas facultades, como lo son las órdenes e instrucciones en forma verbal o escrita, impartidas individual o colectivamente, a los trabajadores. De ahí que se le defina como un "conjunto de facultades". ${ }^{23}$

Por otra parte, no obstante ser calificado el poder de dirección como un derecho subjetivo, se ha discutido si tiene o no la naturaleza de potestativo. Es ampliamente aceptado en la doctrina que el derecho potestativo permite constituir, modificar o extinguir una situación jurídica en ausencia y aun contra la voluntad del sujeto pasivo, quien debe soportar las consecuencias de su ejercicio. ${ }^{24}$ Teniendo ello presente es controvertido si el poder de dirección tiene o no la potencialidad de producir todos o al menos algunos de los efectos del derecho potestativo. Lo que, a su vez, está estrechamente vinculado con su contenido.

Para un sector de la doctrina el poder en cuestión actúa exclusivamente al interior del contrato laboral - del que emana la obligatoriedad del crédito laboral- precisando la prestación de trabajo, con pleno respeto de las

\footnotetext{
${ }^{20}$ Román, cit. (n. 5), p. 114; Poquet, cit. (n. 12), pp. 25-26.

${ }^{21}$ Montoya Melgar, Alfredo, El poder de dirección del empresario, Instituto de Estudios Políticos, Madrid, 1965, pp. 10-20; LuQue PARRA, Manuel, Los límites jurídicos de los poderes empresariales en la relación laboral, Editor J.M. Bosch, Barcelona, 1998, pp. 34-35; Morato, cit. (n. 5), p. 35; PoQuet, cit. (n. 12), pp. 25-26.

${ }^{22}$ Román, cit. (n. 5), pp. 115-116; Poquet, cit. (n. 12), p. 26; Ferrante, cit. (n. 1), p. 28.

${ }^{23}$ Montoya, cit. (n. 21), p. 44; VAldés Dal-Re, Fernando, "Poderes del empresario y derechos de la persona del trabajador", en: Aparicio, J.; Baylos, A. (Coords.), Autoridad y democracia en la empresa, Trotta, Madrid, 1992, p. 31.

${ }^{24}$ El Profesor Larenz define el derecho potestativo como: "aquél que habilita a una persona a establecer una relación jurídica con otra, o a determinarla específicamente en su contenido, modificarla o extinguirla mediante un acto constitutivo unilateral que es, por lo común, una declaración de voluntad", cfr.: Larenz, Karl, Derecho civil. Parte general (Versión castellana de la $3^{\text {a }}$ ed. alemana y notas a cargo de Miguel Izquierdo y Macías - Picavea), Editorial Revista de Derecho Privado, Madrid, 1978, p. 281.
} 
estipulaciones del contrato de trabajo. El mismo no altera, no extingue ni modifica en ningún momento el trabajo convenido, por tanto, no puede ser calificado de derecho potestativo. ${ }^{25}$ Otra posición doctrinaria comprende dentro de la sustancia del poder directivo el ius variandi -que modifica ciertos aspectos del contrato de trabajo- y la extinción del contrato de trabajo a través del despido, ambos efectos propios del derecho potestativo, por lo que naturalmente le reconocen esa calidad. ${ }^{26}$

En nuestra opinión a pesar que el ius variandi es un poder independiente del empleador que, bajo ninguna circunstancia forma parte del poder de dirección y, además, es dudoso que la facultad extintiva del contrato de trabajo integre su contenido $;{ }^{27}$ ambas circunstancias no impiden que el poder de dirección tenga la naturaleza jurídica de derecho potestativo. En virtud de su ejercicio el empleador no solamente especifica la deuda laboral; también, constituye obligaciones y prohibiciones del trabajador que integran y complementan la prestación debida sin modificarla, tal como ocurre, por ejemplo, con las obligaciones y prohibiciones de convivencia, higiene y seguridad contenidas en el reglamento interno (artículos 153 a 157 del Código del Trabajo) y en el reglamento interno de higiene y seguridad (artículo 67 de la Ley $\mathrm{N}^{\circ} 16.744$ y Decreto Supremo $\mathrm{N}^{\circ} 40$ del Ministerio del Trabajo y Previsión Social). Las normas de disciplina laboral y de higiene contenidas en los reglamentos empresariales establecidos en la normativa estatal integran y complementan el contrato de trabajo, constituyendo nuevas obligaciones que deben ser obedecidas por el trabajador. Las mismas no alteran ni constituyen la prestación de trabajo, pero actúan en forma complementaria a las mismas, integrando el crédito laboral, estableciéndose unilateralmente por el empleador como consecuencia del ejercicio del poder directivo empresarial. De esta forma, el poder directivo tiene una función normativa constitutiva, ${ }^{28}$ que va más allá de explicitar la prestación debida, constituyendo obligaciones y prohibiciones que deben ser obedecidas por el trabajador, lo que hace que el mismo sea un derecho subjetivo potestativo. ${ }^{29}$

\footnotetext{
${ }^{25}$ Román, cit. (n. 5), p. 115.

${ }^{26}$ Montoya, cit. (n. 21), p. 7.

${ }^{27}$ Rodríguez - PiÑERo y Bravo - Ferrer, Miguel, "Poder de dirección y derecho contractual”, en: Escudero, R. (Coord.), El poder de dirección del empresario: nuevas perspectivas, La Ley, Madrid, 2005, p. 8.

${ }^{28}$ Cester y Mattarolo, cit. (n. 1), p. 287.

${ }^{29}$ Alonso Olea, Manuel; Casas BaAmonde, María Eugenia, Derecho del Trabajo, Universidad Complutense, Madrid, 1997, p. 377.
} 
En cuando a la calificación del poder de dirección también como poder de mando (utilizándose ambas expresiones como sinónimas en nuestro medio, tal como se ha indicado anteriormente), resulta correcto o no dependiendo del contenido que se atribuya al mismo. Resultaría adecuado referirse al mismo también como poder de mando si se acepta que el núcleo del poder de dirección está constituido por mandar, impartir órdenes e instrucciones, desde que este contenido representa mandatos del empleador hacia sus trabajadores. Por tanto, bajo esta posición -que es la que sostenemos- la expresión poder de mando representa adecuadamente el contenido del poder de dirección. Por el contrario, si se acepta que el contenido del poder de dirección es amplio, incluyéndose dentro del mismo otras facultades del empleador (ius variandi, poder de control, extinción del contrato por decisión del empleador), no es posible emplear las expresiones indicadas como sinónimas, desde que el poder de mando, conforme a esta posición, es solamente un aspecto del poder de dirección. Bajo esta última posición, la expresión poder de mando no representa adecuadamente el contenido que se le otorga al poder de dirección, pudiendo su utilización hacer incurrir en confusiones.

\section{FUNDAMENTO JURÍDICO DEL PODER DE DIRECCIÓN}

No existe discusión en doctrina sobre la legitimad del empleador para ejercer el poder de dirección. Sin embargo, no ha existido ni existe una posición uniforme sobre su fundamentación, lo que se debe en parte a las distintas concepciones que han existido del contrato de trabajo, al cual está vinculado el poder de mando.

Ahora bien, la discusión que existe actualmente en doctrina es: si el contrato de trabajo es o no el exclusivo fundamento del poder de dirección o es complementado con garantías constitucionales del empleador, tales como la libertad de empresa y el derecho de propiedad, la normativa legal y reglamentaria. Controversia que se origina debido a que el contrato de trabajo está inserto en la actividad productiva empresarial, donde se debe organizar el trabajo y coordinar el mismo, que generalmente es llevado a cabo por varios trabajadores.

A continuación, se exponen las distintas posiciones sobre el fundamento del poder de dirección: 


\section{Fundamento exclusivo del contrato de trabajo}

Un sector de la doctrina comparada ha sostenido que el fundamento del poder de dirección es solamente el contrato de trabajo, siendo éste el que se lo concede al empleador, constituyendo una manifestación de la subordinación, ${ }^{30}$ desde que la sumisión del trabajador a la autoridad del empleador constituye una característica esencial del contrato de trabajo. ${ }^{31}$ La naturaleza del mismo, convenido en términos generales, hace surgir un poder que permite "especificar y adaptar continuamente el objeto de la prestación de un trabajo que, por definición se realiza en forma continua, por cuenta ajena y en el ámbito de la organización y dirección del empleador, a diferencia de los que sucede con otros poderes o facultades empresariales que, ejercitadas más allá del objeto del contratado, pueden poner en duda su fundamentación en la relación individual de trabajo". 32

Esta concepción distingue el poder de dirección de las facultades organizativas laborales de la empresa, indicando que el poder de dirección se ejerce y es legítimo al interior del contrato de trabajo, en cambio, las facultades organizativas tienen su título en la libertad de empresa reconocida constitucionalmente. Si bien todas estas prerrogativas persiguen el desarrollo exitoso del proyecto empresarial, ello no impide diferenciar el fundamento jurídico de cada derecho. El poder de dirección deriva del contrato, de forma que no puede trasladarse fuera de él. ${ }^{33}$

La organización productiva de la empresa viene reconocida constitucionalmente al empleador, bajo la que logra satisfacer los requerimientos técnicos y organizativos. La especificación de la prestación laboral y la disciplinaria laboral contribuyen a este fin, siendo su finalidad última. Sin embargo, el contrato de trabajo introduce los elementos suficientes para racionalizar y delimitar el alcance de las facultades directivas, no siendo necesario recurrir a otro fundamento jurídico. ${ }^{34}$

\footnotetext{
${ }^{30}$ Auzero, Gilles; Dockés, Emmanuel, Droit du Travail, Dalloz, París, 2016, 30ª édition, p. 662.

${ }^{31}$ Supiot, Alain, Critique du droit du travail, Quadrige, París, 2015, $3^{\text {a }}$ édition, pp. 113-114.

${ }^{32}$ RomÁn, cit. (n. 5), p. 90.

${ }^{33}$ RoMÁn, cit. (n. 5), p. 90.

${ }^{34}$ Morato, cit. (n. 5), pp. $32-35$.
} 


\section{Fundamento heterónomo del poder de dirección}

Si bien el contrato de trabajo es el fundamento inmediato del poder de dirección y el presupuesto jurídico que habilita su ejercicio, constituyendo una mera expectativa de derecho hasta el perfeccionamiento de la relación laboral, momento a partir del cual comienza a operar en su interior, ${ }^{35}$ las normas constitucionales son el fundamento mediato, que también contribuyen a justificar su existencia. Lo mismo ocurre con normas legales y reglamentarias que regulan ciertos aspectos del poder directivo, de las que emanan la justificación de esta forma de regulación. Las normas estatales permiten fundar esencialmente las órdenes e instrucciones impartidas por el empleador que no dicen relación propiamente con la prestación de trabajo, sino con la disciplina, orden, higiene y seguridad en el trabajo; aspectos no comprendidos por el contrato de trabajo, ni siquiera aceptando la concepción del contrato organización, que no permite justificar debidamente la obligatoriedad de mandatos respecto de personas que no son parte de la relación laboral individual. El pacto contractual regula la relación entre el empleador y el trabajador en lo que dice relación más bien con la prestación de trabajo, pero no regula generalmente la conducta que debe tener el dependiente al interior de la empresa, ni tampoco cómo éste debe comportarse con los compañeros de trabajo, los que son terceros ajenos al pacto laboral individual. Por lo mismo, el contrato de trabajo no puede constituir justificación de estos últimos dos aspectos, al menos no en forma suficiente. De ahí, que las normas estatales contribuyen a justificar el poder de dirección.

Si bien la Constitución Política no se ocupa directamente del poder de dirección, incluye varios preceptos en los que puede encontrarse su fundamento. Ellos son el artículo $19 \mathrm{~N}^{\circ} 21$, que garantiza a todas las personas el derecho a desarrollar cualquier actividad económica, y el $\mathrm{N}^{\circ} 24$ del mismo precepto, que regula el derecho de propiedad.

La libertad económica, reconocida en el artículo $19 \mathrm{~N}^{\circ} 21$ de la Constitución Política, supone la posibilidad de constituir empresas y organizar la actividad empresarial, permitiéndole al empleador organizar la producción de los bienes y servicios, necesitando para ello del poder de dirección, que le permite organizar la prestación de trabajo y la disciplina

\footnotetext{
${ }^{35}$ VARCIN, Francoise, "Le pouvoir patronal de direction", Tesis de Doctorado en Derecho Université Lumiére - Lyon II, Lyon, no publicada, 2000, p. 36.
} 
laboral. De esta forma, la libre iniciativa económica constituye el fundamento constitucional del poder de mando. ${ }^{36}$ Inclusive, se ha llegado a sostener que la fundamentación más relevante de ese poder se encuentra precisamente en el reconocimiento constitucional de la libertad económica. ${ }^{37}$ El poder de dirección debe entenderse como parte integrante del contenido esencial de la libertad de empresa, constituyendo una manifestación de la misma, que utiliza el empresario para que la empresa cumpla su fin. ${ }^{38}$

El derecho de propiedad también constituye fundamento del poder de dirección, ${ }^{39}$ atendido que el hecho que el empleador arriesgue sus bienes en el desarrollo de una actividad económica en que necesita de trabajadores, hace indispensable que le asista el poder de dirección para la correcta gestión de la prestación de trabajo y la disciplina, evitando perjuicios a su propiedad.

El empleador al ser titular de la empresa, de los medios de producción asume un riesgo en el desarrollo de la actividad económica, por ello está dotado de poderes que se le atribuyen desde la Constitución Política para la utilización del factor de trabajo subordinado. La función del poder de dirección del empleador está íntimamente vinculada con la finalidad económica de la empresa que arranca desde la libertad económica y el derecho de propiedad. ${ }^{40}$ Así, la razón última del poder directivo emana del propio sistema económico empresarial instaurado por la Constitución Política a través de las garantías constitucionales mencionadas, siendo las facultades ordenadoras de la conducta y ejecución del crédito laboral expresión y consecuencia de dicho sistema. ${ }^{41}$

En la doctrina española e italiana, también, se ha fundamentado el poder directivo en las normas constitucionales, además, del contrato de trabajo. Tratándose de España, se fundamenta el poder de dirección en el artículo 38 de la Constitución, que regula la libertad de empresa, otorgándole

\footnotetext{
${ }^{36}$ Gamonal y Guidi, cit. (n. 8), p. 89.

${ }^{37}$ Irureta Uriarte, Pedro, "El núcleo laboral del derecho constitucional a la libertad de empresa", Estudios Constitucionales, 2013, Año 11, N², p. 403.

${ }^{38}$ IRURETA, cit. (n. 37), p. 403.

${ }^{39}$ Lizama y Lizama, cit. (n. 9), p. 113.

${ }^{40}$ Savatier, Jean, "Pouvoir patrimonial et direction des personnes, Droit Social, 1982, Nº1, p. 5. El poder de dirección es una esencial herramienta del empleador para responder a las necesidades organizacionales. Y su característica de no necesitar el empleador el consentimiento del trabajador para su ejercicio, para imponer instrucciones unilateralmente, es considerada una esencial función del contrato de trabajo, cfr.: De Stefano, cit. (n. 14), p. 14.

${ }^{41}$ Rivero Lamas, Juan, Limitación de los poderes empresariales y democracia industrial, Universidad de Zaragoza, Zaragoza, 1986, p. 23 ss.
} 
el carácter de fundamento mediato, en tanto el fundamento inmediato viene a ser el contrato de trabajo. ${ }^{42}$ También, la doctrina española ha encontrado fundamento para el poder de dirección del empleador en el artículo 33 de la Constitución, que reconoce la propiedad privada. ${ }^{43}$ Por su parte, en Italia se fundamenta en el artículo 41 de la Constitución Política, disposición que garantiza a todas las personas la libertad de empresa, reconociendo al empresario una autoridad o jerarquía que es inherente a la empresa, de la que es parte esencial el poder de dirección. ${ }^{44}$

La Dirección del Trabajo, igualmente, fundamenta el poder de dirección en las garantías constitucionales anteriormente mencionadas, al concluir que "el sistema jurídico dota al empleador de lo que la doctrina llama el poder de dirección (...) que de alguna manera es manifestación de los derechos constitucionales de propiedad y de la libertad para desarrollar cualquier actividad económica". ${ }^{45}$ Por su parte, la jurisprudencia judicial ha visto en el derecho de propiedad el fundamento del poder de mando. ${ }^{46}$

Descendiendo a la normativa de rango inferior, existen diversas normas legales y reglamentarias que reconocen el poder de dirección del empleador. Así, por ejemplo, el artículo 3, inciso $3^{\circ}$, del Código del Trabajo, define a la empresa como una organización de medios: "ordenados bajo una dirección"; el artículo $4^{\circ}$, inciso $1^{\circ}$ del mismo Código, consagra una presunción de derecho en lo que respecta a la representación del empleador (al indicar que representa a éste y que en tal carácter lo obliga con los trabajadores: "la persona que ejerce habitualmente funciones de dirección

\footnotetext{
42 Valdés, cit. (n. 23), p. 31; Morato, cit. (n. 5), p. 30; Martín Valverde, Antonio; RodríGuez -Sañudo Gutiérrez, Fermín; García Murcia, Joaquín, Derecho del Trabajo, Tecnos, Madrid, 1997, sexta edición, p. 228; Palomeque López, Manuel Carlos; Álvarez de la Rosa, Manuel, Derecho del Trabajo, Editorial Universitaria Ramón Arces, Madrid, 2011, vigésima edición, p. 562; MonTOYA, cit. (n. 2), pp. 31-32; Bejarano, cit. (n. 2), pp. 644-645; PoQuet, cit. (n. 12), pp. 17-18; FABregat Monfort, Gemma, Nuevas perspectivas del poder de dirección y control del empleador, Editorial Bomarzo, Albacete, 2016, p. 9.

43 Poquet, cit. (n. 12), p. 19.

${ }^{44}$ Ghezzi, Georgio; Romagnoli, Umberto, Il rapporto di lavoro, Zanichelli, Bologna, 1987, $2^{\mathrm{a}}$ ed. actualizada, pp. 154 - 155; FerRante, cit. (n. 1), p. 29.

${ }^{45}$ Dirección del Trabajo, dictamen N8005/323, 11 de diciembre de 1995; Dirección del Trabajo, dictamen $N^{\circ} 287 / 14,11$ de enero de 1996; Dirección del Trabajo, dictamen N$^{\circ} 2328 / 130,19$ de julio de 2002; Dirección del Trabajo, dictamen de N²856/162, 30 de agosto de 2002; Dirección del Trabajo, dictamen $\mathrm{N}^{\circ} 2875 / 72,22$ de julio de 2003; Dirección del Trabajo, dictamen N³441/072, 20 de agosto de 2008; Dirección del Trabajo, dictamen N²210/035, 10 de junio de 2009; Dirección del Trabajo, ordinario $\mathrm{N}^{\circ} 4606,4$ de octubre de 2017.
}

${ }^{46}$ Corte de Apelaciones de Copiapó, 17 de octubre de 2016, Rol N82-2016. 
o administración por cuenta o representación de una persona natural o jurídica"); el artículo $5^{\circ}$, inciso $1^{\circ}$ del Código del Trabajo, señala que: "el ejercicio de las facultades que la ley le reconoce al empleador, tiene como límite el respeto a las garantías constitucionales"; y el inciso $4^{\circ}$ del artículo $8^{\circ}$ del referido texto legal prescribe: "No hacen presumir la existencia de contrato de trabajo los servicios prestados en forma habitual en el propio hogar de las personas que los realizan o en un lugar libremente elegido por ellas, sin vigilancia, ni dirección inmediata del que los contrata". ${ }^{47}$

Igualmente, existen normas que consagran reglamentos, que son expresión del poder de dirección, al establecerse a través de los mismos órdenes e instrucciones en forma de obligaciones y prohibiciones. ${ }^{48}$ Así, los artículos 153 y 154 del Código del Trabajo consagran el reglamento interno en empresas, establecimientos, faenas o unidades económicas que ocupen 10 o más trabajadores permanentes, el que debe contener: "las obligaciones y prohibiciones a que deben sujetarse los trabajadores, en relación con sus labores, permanencia y vida en las dependencias de la respectiva empresa o establecimiento" (artículo 153 del Código del Trabajo). Por su parte, los artículos 67 de la Ley $\mathrm{N}^{\circ} 16.744$ y 14 a 20 del Decreto Supremo N40, del Ministerio del Trabajo y Previsión Social, de 1967, regulan el reglamento interno de seguridad e higiene en el trabajo, el cual toda entidad o empresa debe elaborar y mantener al día, independiente del número de trabajadores (artículo 14 del Decreto Supremo $\mathrm{N}^{\circ} 40$ ). Ambos reglamentos tienen como propósito proteger no sólo los intereses del empresario sino también los de los trabajadores, en especial sus derechos a la salud, a la vida, a la integridad física y psíquica, siendo expresiones del poder de dirección; justificándose su procedencia como consecuencia de las normas estatales que los regulan, las normas constitucionales que regulan la libertad de empresa y el derecho de propiedad y, finalmente, el contrato de trabajo, desde que, igualmente, contienen disposiciones que precisan el crédito laboral y persiguen su correcta ejecución $\mathrm{y}$, por tanto, el debido cumplimiento del contrato de trabajo.

\footnotetext{
${ }^{47}$ IruRETA, cit. (n. 37), p. 403.

${ }^{48}$ Cester y Mattarolo, cit. (n. 1), p. 351.
} 


\section{FACULTADES INTEGRANTES DEL PODER DE DIRECCIÓN: SU CONTENIDO}

Es fácil advertir en la doctrina y jurisprudencia el elevado grado de dispersión que existe sobre el conjunto de facultades que integran el poder de dirección, comprendiendo, a veces, otros poderes del empleador dentro de su contenido, por lo mismo, no existe claridad del quantum de poderes de que está dotado el empleador ni menos sobre su contenido. Lo que no solo tiene lugar en la realidad nacional sino también en otros países. Por ejemplo, en Francia, los poderes del empleador se clasifican generalmente en poder de dirección, poder reglamentario y poder disciplinario, aludiendo a la clásica separación de poderes ejecutivo, legislativo y judicial. ${ }^{49}$ En Italia, no existe claridad si los poderes del empresario son solo el poder de dirección, el ius variandi, el poder disciplinario, además, de agregar el poder de control, como un poder distinto al poder de dirección, o bien, existe un solo poder: el de dirección, que abarca todos los otros poderes. ${ }^{50}$ En España existe la misma confusión que en Italia, existiendo posiciones que distinguen claramente los cuatro poderes indicados, ${ }^{51}$ otras que optan por un concepto amplio de poder directivo, omnicomprensivo de todas las otras facultades laborales empresariales, ${ }^{52}$ otras posiciones que sostienen

\footnotetext{
49 Auzero y Dockés, cit. (n. 30), p. 662; Mazeaud, Antoine, Droit du travail, Montchrestien, Paris, 2012, 8 a édition, p. 92.

${ }^{50}$ Pessi, Roberto, Il potere direttivo dell'imprenditore ed i suoi nuovi limité dopo la legge 29 maggio 1970. N. 300", Rivista Diritto Lavoro, 1973, N¹, p. 69. Para Pera, el poder de dirección opera en dos direcciones: la de impartir órdenes para la ejecución del trabajo, incluyendo las variaciones del ius variandi, el objeto de identificar la prestación, y las disposiciones de tipo disciplinario, cfr.: PERA, Giusseppe, Diritto del lavoro, Cedam, Padova, 1984, p. 575. Por su parte, Ghezzi y Romagnoli indican que el poder directivo aparece referido a las funciones, tiempo y lugar de la prestación, separado del poder de control y disciplinario, sin los cuales el acreedor no puede satisfacer su interés, cfr.: Ghezzi y Romagnoli, cit. (n. 44), pp. 154-155. Más reciente Mazzotta, Oronzo, Diritto del Lavoro, Giuffré Editore, Milano, 2011, quarta edizione, p. 524; Vallebona, Antonio, Instituzioni di Diritto del Lavoro. II. Il rapporto di Lavoro, CEDAM, Milano, 2012, $8^{\text {a }}$ edizione, p. 144; Ferrante, cit. (n. 1), p. 40, indican que el empleador está dotado de los poderes de dirección, de control y disciplinario, pronunciándose en similares términos que Ghezzi y Romagnoli.

${ }^{51}$ Morato, cit. (n. 5), p. 30.

${ }^{52}$ Cruz Villalón, Jesús, Las modificaciones de la prestación de trabajo, Ministerio del Trabajo y Seguridad Social, Madrid, 1983, p. 20; Alonso García, Manuel, Curso de Derecho del Trabajo, Ariel, Barcelona, 1985, $9^{\mathrm{a}}$ ed., p. 528. Fundando en que los poderes del empleador tienen como fundamento último la libertad de empresa, el Profesor Martín Valverde postula: "una configuración unitaria del poder de dirección como haz o conjunto de facultades que definen la posición del empresario en las relaciones laborales", cfr.: MARTín VALVERde, Antonio, "El ordenamiento laboral en la jurisprudencia del Tribunal Supremo”, Revista Política Social, 1983, N¹37, pp. 142-143; FABREGAT, cit. (n. 42), p. 17.
} 
que el empleador tiene dos poderes laborales, cuales son: el de dirección y el disciplinario..$^{53}$ Otros autores españoles que indican que el empleador tiene tres poderes: el poder de dirección, el disciplinario y el de control ${ }^{54} \mathrm{y}$, finalmente, se ha indicado en España que el empleador está dotado de los poderes de dirección, ius variandi y disciplinario. ${ }^{55}$

En nuestro medio existen dos posiciones sobre cuál es el contenido del poder de dirección. Una concepción amplia del poder de dirección que, incluye dentro de su contenido las facultades administrativas laborales propias de la libertad de empresa y, también, los poderes disciplinario, de control y el ius variandi; y una concepción restringida o de contenido propio del poder de dirección que distingue claramente el poder de dirección del resto de derechos subjetivos laborales del empleador.

\section{Posición sobre el contenido amplio del poder de dirección}

Se acepta comúnmente por un sector de la doctrina ${ }^{56}$ y jurisprudencia una concepción amplia del poder de dirección que integra las más amplias facultades empresariales, con el propósito que el empleador cuente con las herramientas jurídicas necesarias para realizar una gestión eficiente del trabajo. Así, se ha sostenido que el mismo tiene una doble dimensión: general (como poder de organizar laboralmente la empresa) y singular (como poder de ordenar las concretas prestaciones de los trabajadores individuales). ${ }^{57}$ Dentro de las primeras se comprenden las facultades de la empresa para determinar el número de trabajadores a contratar, las modalidades del contrato de trabajo, las remuneraciones a convenir, las jornadas laborales a cumplir, la planilla de trabajadores y tipo de cargo, la externalización del trabajo a través, por ejemplo, de la subcontratación o el suministro de personal, la extinción del contrato de trabajo ${ }^{58}$ entre otras decisiones de índole laboral. ${ }^{59}$

\footnotetext{
${ }^{53}$ Alonso Olea, Manuel; Casas Banmonde, María Emilia, Derecho del Trabajo, Editorial Civitas S.A., Madrid, 2006, 20ª ed. Actualizada, pp. 506-508.

${ }^{54}$ Cruz Villalón, Jesús, Compendio de Derecho del Trabajo, Tecnos, Madrid, 2010, tercera edición, p. 193.

55 Poquet, cit. (n. 12), p. 27 y ss.

${ }^{56}$ IrURETA, cit. (n. 37), pp. 403-404.

${ }^{57}$ Montoya (n. 2), p. 135; Montoya, cit. (n. 21), pp. 576 - 578.

${ }^{58}$ Corte de Apelaciones de Puerto Montt, 30 de octubre de 2017, Rol N¹68-2017; Corte de Apelaciones de Santiago, 16 de marzo de 2018, Rol N¹948-2017.
}

${ }^{59}$ Montoya, cit. (n. 2), p. 136. 
Se trata de las facultades administrativas laborales necesarias para llevar a cabo la actividad empresarial a través del trabajo dependiente. Por su parte, el aspecto individual o singular, otorga al empleador el poder de definir las prestaciones concretas de los trabajadores mediante órdenes e instrucciones oportunas, y fiscalizar su cumplimiento. Asimismo, se comprenden el ius variandi, el poder de control y el poder disciplinario dentro del conjunto de facultades directivas en su concepción amplia. ${ }^{60}$

La Dirección del Trabajo ha señalado reiteradamente "al empleador le es reconocido el ejercicio de una serie de facultades o prerrogativas que tienen por objeto el logro del referido proyecto empresarial en lo que al ámbito laboral se refiere, y que se traducen en la libertad para contratar trabajadores, ordenar las prestaciones laborales, adaptarse a las necesidades de mercado, controlar el cumplimiento y ejecución del trabajo convenido, y sancionar las faltas o los incumplimientos contractuales del trabajador. Estas facultades, que responden a lo que genéricamente se denomina poder de dirección -comprendiendo en este concepto amplio tanto el poder de dirección strictu sensu como el disciplinario". ${ }^{61}$ De esta forma, el organismo administrador laboral reconoce expresamente como contenido del poder directivo las dimensiones general o colectiva y singular o individual, además del poder disciplinario, ${ }^{62}$ lo que también es compartido por un sector de la doctrina nacional ${ }^{63}$ y extranjera, ${ }^{64}$ fundado en que serían componentes

\footnotetext{
${ }^{60}$ Martín, RodrígueZ - SAÑUdo y García, cit. (n. 42), pp. 228-229.

${ }^{61}$ Dirección del Trabajo, dictamen N²856/162, 30 de agosto de 2002; Dirección del Trabajo, dictamen N³406/054, 3 de septiembre de 2014. En similar sentido: Dirección del Trabajo, dictamen N626/13, 21 de enero de 1991; Dirección del Trabajo, ordinario N²292, 29 de mayo de 2017; Dirección del Trabajo, ordinario N4606, 4 de octubre de 2017; Dirección del Trabajo, ordinario N³739, 13 de julio de 2018; Dirección del Trabajo, ordinario N4457, 23 de agosto de 2018.

${ }^{62}$ Dirección del Trabajo, dictamen N²084/104, 17 de abril de 1987; Dirección del Trabajo, dictamen N³659/180, 2 de octubre de 2001; Dirección del Trabajo, dictamen N²856/162, 30 de agosto de 2002; Dirección del Trabajo, dictamen $N^{\circ} 2328 / 130,19$ de julio de 2002; Dirección del Trabajo, dictamen N³363/103, 20 de agosto de 2003; Dirección del Trabajo, dictamen N5073/082, 16 de diciembre de 2014; Dirección del Trabajo, ordinario N¹163, 2 de marzo de 2018.

${ }^{63}$ Ugarte, cit. (n. 8), pp. 10-12; Gajardo Harboe, María Cristina, "La obligación de seguridad", Revista Chilena de Derecho del Trabajo y de la Seguridad Social, 2014, Vol. 9, N², p. 20: "Son inherentes al poder de dirección la potestad disciplinaria, que surge ante el incumplimiento por parte del trabajador de las órdenes e instrucciones que el empleador le imparte y la potestad reglamentaria, con la posibilidad de traducir tales órdenes e instrucciones en reglamentos internos, instructivos y códigos de conducta"; Thayer, William; Novoa, Patricio, Manual de Derecho del Trabajo, Editorial Jurídica de Chile, Santiago, 2010, $5^{\mathrm{a}}$ ed. Actualizada, T. III, p. 114.

${ }^{64}$ En la doctrina comparada véase: CRUZ, cit. (n. 2), p. 237; MARTín, cit. (n. 52), pp. 142-143; VALDÉs, cit. (n. 23), pp. 31-32.
} 
de una misma realidad, identificando al poder disciplinario como la última fase del poder directivo. También ha reconocido la Dirección del Trabajo el "poder de control de los trabajadores por parte del empleador como una de las manifestaciones fundamentales del poder jurídico de mandato". ${ }^{65}$ En cuanto al ius variandi, ha sostenido reiteradamente que "es una facultad que tiene el empleador, derivada de su potestad o poder de dirección, para alterar unilateralmente los límites de la prestación de trabajo"; ${ }^{66}$ posición compartida, también, por un sector de la jurisprudencia judicial, ${ }^{67}$ por la doctrina nacional mayoritaria, ${ }^{68} \mathrm{e}$ inclusive por un sector de la doctrina extranjera. ${ }^{69}$

No compartimos el concepto extensivo del poder de dirección que incorpora una dimensión general en el mismo, puesto que lo que hace es confundir el poder de dirección con facultades administrativas y organizativas también derivadas de la libertad de empresa y derecho de propiedad al igual que el poder de dirección. El aspecto general o colectivo forma parte del contenido de las facultades de administración y dirección de la empresa, que intervienen en un poder de ordenación patrimonial, perteneciendo a

\footnotetext{
${ }^{65}$ Dirección del Trabajo, dictamen $N^{\circ} 195 / 8,17$ de enero de 2002; Dirección del Trabajo, ordinario ํ5101, 7 de octubre de 2015; Dirección del Trabajo, ordinario $N^{\circ} 5417,8$ de noviembre de 2016.

${ }^{66}$ Dirección del Trabajo, dictamen N³351/0185, 9 de junio de 1997; Dirección del Trabajo, dictamen $\mathrm{N}^{\circ} 2703 / 0042,19$ de mayo de 2016; Dirección del Trabajo, ordinario $\mathrm{N}^{\circ} 4558,6$ de septiembre de 2016; Dirección del Trabajo, ordinario N5719, 25 de noviembre de 2016; Dirección del Trabajo, ordinario $\mathrm{N}^{\circ} 0345,20$ de enero de 2017; Dirección del Trabajo, ordinario $\mathrm{N}^{\circ} 1504,5$ de abril de 2017; Dirección del Trabajo, ordinario $\mathrm{N}^{\circ} 5030,26$ de octubre de 2017.

${ }^{67}$ Corte de Apelaciones de Copiapó, 17 de octubre de 2016, Rol N ${ }^{\circ} 82-2016$; Corte de Apelaciones de Antofagasta, 12 de mayo de 2017, Rol N`51-2017; Corte de Apelaciones de Rancagua, 16 de mayo de 2017, Rol N`198-2016; Corte de Apelaciones de Iquique, 15 de junio de 2017, Rol N³9-2017; Corte de Apelaciones de Valdivia, 9 de marzo de 2019, Rol №2-2019; Corte de Apelaciones de La Serena, 9 de abril de 2019, Rol N³11-2018.

${ }^{68}$ Ugarte, cit. (n. 8), pp. 10-11; Gamonal y Guidi, cit. (n. 8), p. 91.

${ }^{69}$ Montoya, cit. (n. 2), pp. 135-136; Montoya, cit. (n. 21), pp. 113 y 183-187; Montoya Melgar, Alfredo, "Dirección de la actividad laboral. Art. 20 E.T.", en: Borrajo, E (Dir.), Comentarios a las leyes laborales, Edersa, Madrid, 1985, T. V, p. 133 ss.; Bejarano, cit. (n. 2), pp. 645-646; Garrigues GimÉNEZ, Amparo, "Obediencia debida y desobediencia del trabajador: su tratamiento en la última jurisprudencia", Tribunal Social, 2000, N¹20, pp. 40 y 50; Martínez Rocamora, Luis, Decisiones empresariales y principio de igualdad, Cedecs, Barcelona, 1998, pp. 36-37; Alonso y CASAs, cit. (n. 53), pp. 507-508; MARTín, RodrígueZ - SAÑUdo y García, cit. (n. 42), pp. 228-229; RodríGUeZ INIESTA, Guillermo, "Facultades empresariales de control y vigilancia de la salud 'versus' derecho a la intimidad de los trabajadores", en: Escudero, R. (Coord.), El poder de dirección del empresario: nuevas perspectivas, La Ley, Madrid, 2005, p. 190; FABregat, cit. (n. 42), p. 17; SteWART, cit. (n. 5), p. 282.
} 
un momento anterior al contrato de trabajo o a su extinción, ${ }^{70}$ no estando ligado a una situación de sujeción del trabajador. ${ }^{71}$ Por el contrario, el poder de dirección corresponde al empleador en cuanto parte contratante de la relación laboral, expresión de la subordinación, y su ejercicio responde a la ejecución misma del contrato. ${ }^{72} \mathrm{El}$ mismo opera durante la vigencia del contrato de trabajo, ejerciéndose e imponiéndose al trabajador durante su desarrollo. No obstante, el fundamento constitucional del poder de mando, el mismo solamente tendrá eficacia y se ejercerá una vez perfeccionado el negocio jurídico laboral, operando en su interior, no teniendo vigencia fuera del mismo ni en su ausencia ni en su extinción.

Así las cosas, se distinguen claramente los poderes administrativos u de "organización del trabajo" "73 de que dispone el empresario del poder de dirección propiamente tal. Los primeros operan sobre la constitución y extinción de la relación laboral. Poderes constitutivos y extintivos del contrato "frente a los que el trabajador no se encuentra propiamente subordinado, aunque condicionen la subsistencia del contrato de trabajo y, por ello su propia subsistencia"; ${ }^{74}$ en cambio, el poder de dirección surge por efecto del contrato y depende de su subsistencia, ${ }^{75}$ operando en su interior especificando el objeto de la prestación e impartiendo mandatos para mantener la disciplina laboral.

En cuanto a los poderes de control, disciplinario e ius variandi, tienen un contenido diferente al poder directivo, que lo hacen ser derechos distintos del empleador, no incluyéndose los mismos ni siquiera en un concepto amplio de poder de dirección. El hecho que todos sean instrumentos de que dispone el empleador para lograr su proyecto empresarial no los hacer ser uno solo.

\section{Posición sobre el contenido propio del poder de dirección}

No obstante que nuestra jurisprudencia y doctrina mayoritaria han configurado las prerrogativas de ius variandi, control empresarial y

\footnotetext{
${ }^{70}$ Román, cit. (n. 5), pp. 94-95; Morato, cit. (n. 5), p. 38.

${ }^{71}$ Maria Mastinu, Enrico, "La procedimentalización sindical del ejercicio de los poderes y prerrogativas del empresario, en: Escudero, R. (Coord.), El poder de dirección del empresario: nuevas perspectivas, La Ley, Madrid, 2005, p. 270.

72 Román, cit. (n. 5), pp. 94-95; Morato, cit. (n. 5), p. 38.

${ }^{73}$ Maria, cit. (n. 71), p. 270.

${ }^{74}$ Rodríguez - Piñero, cit. (n. 27), p. 8.

${ }^{75}$ Rodríguez - PiÑERo, cit. (n. 27), p. 9
} 
disciplinarias como partes integrantes del poder directivo, lo cierto es que no son parte de su contenido. Se trata de poderes diferentes, todos dirigidos a que se ejecute debidamente el proyecto empresarial y la empresa pueda cumplir sus objetivos, constituyendo instrumentos jurídicos de que dispone el empleador para lograr su cometido. Igualmente, existen otras facultades que no forman parten del poder de dirección, como lo son las facultades administrativas o de organización del trabajo, las cuales son parte de las facultades generales de administración derivadas de la libertad de empresa. A continuación, se expondrá con detalle las razones de la exclusión de ciertas facultades del contenido del poder de dirección como también cuál es su contenido exacto.

(2.1) El poder disciplinario no integra el poder de dirección.

El poder disciplinario está íntimamente relacionado al poder de dirección, contribuyendo a garantizar su efectividad. De este modo, el poder de dirección y el poder disciplinario están muy relacionados, sosteniéndose por la doctrina que el segundo actúa como la consecuencia penal de la trasgresión del primero por parte del trabajador. ${ }^{76} \mathrm{El}$ poder disciplinario constituye así el complemento ideal e imprescindible del poder de dirección, debido a que este último sería un "mero poder moral" " si no se permitiera al empleador sancionar los incumplimientos de la órdenes generales y especiales que imparte a sus trabajadores. El poder disciplinario encuentra así su justificación, su razón de existir, constituyendo uno de los medios más eficaces para garantizar el orden organizativo de la empresa y, en último término, el fin productivo de aquélla. ${ }^{78}$

No obstante su estrecha vinculación existe una clara distinción entre ambos poderes; al ser el poder disciplinario instrumental al poder de dirección, actuando cuando este último ha resultado lesionado, no pueden confundirse, diferenciándose claramente. ${ }^{79}$ El poder de dirección permite impartir órdenes,

\footnotetext{
${ }^{76}$ Rodríguez Rodríguez, Emma, El poder disciplinario y la negociación colectiva, Editorial Comares, Granada, 2008, p. 16.

${ }^{77}$ Alonso y Casas, cit. (n. 53), pp. 425-426.

${ }^{78}$ Monstuschi, Luigi, Potere disciplinare e rapporto di lavoro, Giuffrè Editore, Milano, 1973, p. 10; Terradillos OrmaetXea, Edurne, El poder disciplinario empresarial. Principios y garantías, Tirant lo Blanch, Valencia, 2004, p. 16.

${ }^{79}$ Román, cit. (n. 5), pp. 119-121; Morato, cit. (n. 5), pp. 46-48; Poquet, cit. (n. 12), p. 35; Gamonal y Guidi, cit. (n. 8), pp. 100-103; Lizama y Lizama, cit. (n. 9), pp. 115-116; Fernández Toledo, Raúl, "Precisiones sobre el poder disciplinario del empleador", Revista Chilena de Derecho del Trabajo y de la Seguridad Social, 2015, Vol. 6, N¹1, pp. 56-58.
} 
mientras que el poder disciplinario permite imponer sanciones. No es una distinción formal, sino de contenido, hay una verdadera separación por el objeto. ${ }^{80}$ De este modo, a pesar de las conexiones que puedan existir entre el poder de dirección y el poder disciplinario y elementos en común, como titularidad del poder, destinatarios de los mismos, son distintos y autónomos, esencialmente en cuanto a su objeto, no pudiendo subsumirse uno bajo el otro. ${ }^{81}$ El poder disciplinario tiene reglas diferentes y un objeto diferente, que no le permite subsumirse bajo el poder de dirección. Por tanto, el poder de dirección no comprende las facultades sancionadoras del empleador. ${ }^{82}$

Si bien, ambos poderes se dirigen a tutelar el interés del empleador, por ello su conexión, tienen un campo de actuación diverso. El empleador sólo recurrirá al ejercicio del poder disciplinario cuando las medidas directivas no sean idóneas o suficientes para organizar la empresa, debido, a la concurrencia de un incumplimiento laboral por parte del trabajador. ${ }^{83}$ El poder disciplinario queda supeditado a la eficacia del poder de dirección, de manera que solamente entrará a actuar cuando este último ha resultado quebrantado o sus mecanismos son insuficientes para mantener el orden en la empresa. Se trata de un derecho de última ratio de que goza el empleador, que precisa de un incumplimiento laboral, para poder ser ejercicio. Como consecuencia de ello, se deben observar diversos principios que restringen este poder sancionador, como lo son los principios de tipicidad, non bis in idem, de proporcionalidad, entre otros. ${ }^{84}$

(2.2) Las facultades de vigilancia y control no forman parte del poder de dirección.

En íntima conexión con el poder de mando se encuentran las

\footnotetext{
${ }^{80}$ Montoya, cit. (n. 21), p. 142-143.

${ }^{81}$ FERNÁNDEZ, cit. (n. 79), p. 58.

82 Montoya, cit. (n. 21), p. 113; Román, cit. (n. 5), pp. 117 y 119-121; Morato, cit. (n. 5), pp. 4647; PoQuet, cit. (n. 12), p. 32: "la facultad disciplinaria no forma parte del poder de dirección, sino que constituye una facultad con autonomía propia, diferente de la del poder de dirección, aunque íntimamente ligada al mismo, pudiendo sostenerse que forman dos caras de una misma moneda, para cada una con un régimen jurídico diferente y con sustantividad y autonomía propia. Por tanto, la relación entre el poder de dirección y el disciplinario es complementaria, pues éste sirve de apoyo al de dirección, y en cierta manera, al de vigilancia y al de control".

${ }^{83}$ Terradillos, cit. (n. 78), p. 19.

${ }^{84}$ Para mayor detalle sobre el poder disciplinario del empleador en el derecho nacional véase: Fernández Toledo, Raúl, El poder disciplinario del empleador, Thomson Reuters - La Ley, Santiago, 2016.
} 
facultades de control y vigilancia sobre el trabajo realizado y el grado de cumplimiento de las órdenes e instrucciones impartidas por el empleador. Se trata del poder que se encuentra ligado con mayor intensidad al poder de dirección, sosteniéndose tradicionalmente que el mismo forma parte de la sustancia del poder de dirección, constituyendo un apéndice del mismo. ${ }^{85}$ Sin las facultades de control y vigilancia no existiría forma que el empresario corrobore el cumplimiento de los mandatos impartidos, pudiendo ser fácilmente burlados los mismos de no contar el empleador con las facultades de vigilancia y control. "Por tanto, será la comprobación del efectivo cumplimiento de las obligaciones laborales o de su inobservancia la que permita que las prerrogativas empresariales de mando se ejecuten de manera real y no meramente ficticia". ${ }^{86}$

Si bien mayoritariamente se ha señalado que las facultades señaladas configuran una faceta más del poder directivo, formando parte de su contenido $^{87}$-lo que también es defendido por un sector de la doctrina extranjera $^{88}$ - lo cierto es que constituyen un poder independiente pero vinculado al poder directivo y que permite garantizar la efectividad de este último como también la correcta ejecución de la prestación de trabajo pactada en el contrato de trabajo, en toda y cada una de sus etapas. ${ }^{89}$ Reducir su contenido a un mero aspecto del poder de mando sería simplificar una realidad mucho más compleja, que conduce a configurar las facultades de

\footnotetext{
${ }^{85}$ Fernández Avilés, José Antonio; Rodríguez Rico RoldÁn, Victoria, "Nuevas tecnologías y control empresarial de la actividad laboral en España”, Labour \& Law Issues, 2016, Vol. 2, ํ1, p. 50.

${ }^{86}$ Morato, cit. (n. 5), pp. 46-47.

${ }^{87}$ Dirección del Trabajo, dictamen $N^{\circ} 195 / 8,17$ de enero de 2002; Dirección del Trabajo, ordinario N5101, 7 de octubre de 2015; Dirección del Trabajo, ordinario N5417, 8 de noviembre de 2016.

${ }^{88}$ Fernández López, María Fernanda, El poder disciplinario en la empresa, Editorial Civitas S.A., Madrid, 1991, p. 329; CRUz, cit. (n. 2) , p. 235; GoÑ SEIN, José Luis, El respeto a la esfera privada del trabajador: un estudio sobre los límites del poder de control empresarial, Editorial Civitas S.A., Madrid, 1988, p. 111; MontoyA, cit. (n. 2), p. 136; Montoya, cit. (n. 21), p. 141-143 y 153; VALDÉS, cit. (n. 23), pp. 31-32; Rodríguez, cit. (n. 69), p. 190; PoQuet, cit. (n. 12), pp. 34-35; Fernández y Rodríguez, cit. (n. 85), p. 50; CARABelli, Umberto, Organizzazione del lavoro e professionalità: una riflessione su contratto di lavoro e post-taylorismo, Centro Studi di Diritto del Lavoro Europeo “Massimo D’Antona”, Catania, 2003, p. 42; FABregat, cit. (n. 42), p. 17; Barraco, Enrico; Sitzia, Andrea, Potere di controllo e privacy. Lavoro, riservatezza e nuove tecnología, Wolters Kluwer, Vicenza, 2016, p. 1.

${ }^{89}$ RomÁn, cit. (n. 5), pp. 118-119; Morato, cit. (n. 5), pp. 48-50. Un sector de la doctrina italiana también reconoce el carácter autónomo del poder de control, destacando entre otros: VENEZIANI, Bruno, I controlli dell'impeditore e i contratti di lavoro, Cacucci, Bari, 1975, p. ss.; Bellavista, Alessandro, Il controllo sui lavoratori, Giappichelli, Torino, 1995, p. 1 ss.; Ferrante, cit. (n. 1), p. 40; Mazzotta, cit. (n. 50), p. 524. VAllebona, cit. (n. 50), p. 144. Véase un resumen de las distintas posiciones sobre el poder de control en la doctrina italiana en: CesTer y MATTAROLO cit. (n. 1), pp. 561-564.
} 
control y vigilancia como un poder vinculado a los demás que detenta el empleador, pero autónomo. ${ }^{90}$

El poder de vigilancia y control emana directamente del contrato de trabajo, siendo una expresión de la subordinación, tal como lo ha reconocido la jurisprudencia ${ }^{91}$ y doctrina. ${ }^{92}$ El control y vigilancia de la prestación de trabajo y las instrucciones impartidas es una característica inmanente de la relación de trabajo subordinada, reconocida al empleador por detentar tal calidad y ser el acreedor de la prestación de trabajo. ${ }^{93}$ Sin embargo, para su ejercicio, según lo ha resuelto la Dirección del Trabajo, debería estar contemplado en el reglamento interno de orden, higiene y seguridad establecido en conformidad al Código del Trabajo y respetar los derechos fundamentales de los trabajadores, tal como lo dispone el artículo 154 inciso $2^{\mathrm{o}}$ del Código del ramo. ${ }^{94}$ Tales requisitos se exigen por el organismo administrativo como presupuestos para su correcto ejercicio. Sin embargo, es dudosa la exigencia de la necesaria regulación de toda medida de control en el reglamento interno, desde que el artículo 154 inciso $2^{095}$ si

\footnotetext{
${ }^{90}$ Marín Alonso, Inmaculada, El poder de control empresarial sobre el uso del correo electrónico en la empresa, Tirant lo Blanch, Valencia, 2005, p. 181; Morato, cit. (n. 5), p. 49. La jurisprudencia judicial nacional ha ido reconociendo paulatinamente el carácter autónomo del poder de control y vigilancia, refiriéndose al mismo como poder de inspección (Corte de Apelaciones de Santiago, 9 de febrero de 2018, Rol N²134-2017), facultad de vigilancia y control (Corte Suprema, 4 de septiembre de 2017, Rol N¹5.403-2017), o simplemente, como control (Corte de Apelaciones de Antofagasta, 14 de octubre de 2016, Rol N¹85-2016).

${ }^{91}$ Dirección del Trabajo, dictamen No1043/42, 8 de febrero de 1995; Dirección del Trabajo, dictamen N³992/160, 31 de agosto de 2004; Dirección del Trabajo, dictamen N²127/020, 6 de junio de 2014; Dirección del Trabajo, ordinario $\mathrm{N}^{\circ} 6342,2$ de diciembre de 2015; Dirección del Trabajo, ordinario $\mathrm{N}^{\circ} 6463,10$ de diciembre de 2015; Dirección del Trabajo, dictamen N3537/63, 6 de julio de 2016; Dirección del Trabajo, ordinario $\mathrm{N}^{\circ} 4064,4$ de agosto de 2016; Dirección del Trabajo, ordinario $\mathrm{N}^{\circ} 800$, 16 de febrero de 2017.

${ }^{92}$ Cester y Mattarolo, cit. (n. 1), pp. 562-563; De Stefano, cit. (n. 14), pp. 13-14.

${ }^{93}$ Cester y Mattarolo, cit. (n. 1), pp. 562-563; Juzgado de Letras y del Trabajo de Victoria, 11 de octubre de 2018, RIT O-7-2018.

${ }^{94}$ Dirección del Trabajo, dictamen №195/8, 17 de enero de 2002; Dirección del Trabajo, dictamen $\mathrm{N}^{\circ} 2328 / 130,19$ de julio de 2002; Dirección del Trabajo, dictamen No2852/158, 30 de agosto de 2002; Dirección del Trabajo, dictamen N³276/173, 16 de octubre de 2002; Dirección del Trabajo, dictamen N³031/046, 12 de julio de 2010; Dirección del Trabajo, ordinario №5101, 7 de octubre de 2015; Dirección del Trabajo, ordinario $N^{\circ} 5417,8$ de noviembre de 2016; Dirección del Trabajo, ordinario $\mathrm{N}^{\circ} 3125,9$ de julio de 2018.

${ }^{95}$ El artículo 154 inciso $2^{\circ}$ del Código del Trabajo indica: "Las obligaciones y prohibiciones a que hace referencia el número 5 de este artículo, y, en general, toda medida de control, sólo podrán efectuarse por medios idóneos y concordantes con la naturaleza de la relación laboral y, en todo caso, su aplicación deberá ser general, garantizándose la impersonalidad de la medida, para respetar la dignidad del trabajador".
} 
bien está ubicado en el capítulo del reglamento interno, no contempla ni siquiera remotamente como requisito que se contemplen en el reglamento empresarial las medidas de control y sus requisitos de procedencia. Por tanto, el empleador podría utilizar distintos mecanismos de fiscalización en la medida que respete los derechos fundamentales de los trabajadores, que constituye un límite de todo poder del empleador (artículo 5 inciso $1^{\circ}$, Código del Trabajo), tal como se lo permite el contrato de trabajo.

El cometido principal de las prerrogativas de vigilancia y control es verificar la correspondencia entre el comportamiento del dependiente y los mandatos del empleador, es decir, comprobar que las órdenes e instrucciones verbales y escritas impartidas en virtud del poder de dirección fueron cumplidas por el dependiente. Ahora bien, tales poderes abarcan un campo de actuación más amplio que el poder directivo, pues el empresario, en conformidad a los mismos, puede certificar el cumplimiento debido de la prestación laboral y demás obligaciones y prohibiciones establecidas en el contrato de trabajo y en el instrumento colectivo. El acreedor del crédito podrá controlar "el cumplimiento total de las obligaciones, o mejor, de la prestación de trabajo de todos y cada uno de los trabajadores en todas y cada una de sus facetas de ejecución". ${ }^{96}$

Si bien, generalmente se emplean como sinónimos los términos vigilancia y control, refiriéndose indistintamente ambos a la supervisión del trabajador durante su permanencia y ejecución del trabajo convenido, se les distingue en doctrina por su intensidad de fiscalización. La vigilancia alude a la mayor continuidad en la labor de verificación, dirigiendo su campo de actuación a la prestación laboral que se ejecuta dentro de los márgenes del poder directivo, mientras que el control conllevaría un seguimiento de menor intensidad, corroborando generalmente el trabajo inicial instruido con el final ejecutado. ${ }^{97} \mathrm{El}$ control generalmente es más común en trabajadores que ejecutan labores fuera del lugar de trabajo, a distancia o a domicilio, donde lo más relevante es el resultado final de la labor encomendada. En cambio, la vigilancia tiene lugar generalmente en las labores realizadas en el lugar de trabajo controlado por el empleador, motivado también por

\footnotetext{
${ }^{96}$ García Ninet, José, “Artículo veinte. Dirección y control de la actividad laboral”, en: Departamento de Derecho del Trabajo Universidad de Valencia (Coords.), El Estatuto de los Trabajadores. Comentarios a la Ley 8/1980, de 10 de marzo, Edersa, Madrid, 1981, p. 164.

${ }^{97}$ Goñi, cit. (n. 88), pp. 110-111; Martínez, cit. (n. 69), p. 44; Del Valle Villar, José Manuel, "El derecho a la intimidad del trabajador durante la relación de trabajo", Actualidad Laboral, 1991, Vol. III, p. 492; MORATO, cit. (n. 5), p. 49.
} 
exigencias propias de la obligación de seguridad, que exige vigilar el trabajo ordenado..$^{98}$

Según se puede observar el poder de vigilancia y control no se limita solamente a comprobar la sujeción del trabajador al conjunto de órdenes e instrucciones impartidas por el empleador en virtud del poder directivo, sino que abarca otros extremos, como lo son: la ejecución de la prestación de trabajo conforme al contrato individual de trabajo $0^{99} \mathrm{y}$ a la normativa estatal que lo integra y complementa, tal como lo dispone el artículo 1546 del Código Civil; la vigilancia y control del estado de salud de los trabajadores, ${ }^{100}$ según la labor ejecutada, con el propósito de comprobar que el trabajador tiene salud compatible para el cargo. ${ }^{101}$ Es en virtud de este campo de actuación que no se le puede identificar como una manifestación del poder de dirección, desde que actúa más allá del mismo. Solamente existe una relación estrecha, desde que el poder de control y vigilancia permite garantizar su efectividad a través de su fiscalización, persiguiendo ambos que el empleador pueda realizar su proyecto empresarial a través de una correcta ejecución de la prestación de trabajo subordinado.

\section{(2.3) Ius variandi y poder de dirección.}

No existe duda en cuanto a la conceptualización del ius variandi, siendo el derecho subjetivo potestativo que permite al empleador alterar unilateralmente ciertos aspectos del contrato de trabajo conforme a las normas legales que lo regulan. Constituye una excepción al principio de la modificación por mutuo acuerdo de las partes del negocio laboral.

Para que tenga lugar es necesario una cobertura legal, operando, por tanto, en todos aquellos supuestos en que el empleador en virtud de una norma jurídica puede efectuar modificaciones al contrato laboral, incurriendo

\footnotetext{
${ }^{98}$ Rodríguez, cit. (n. 69), p. 190; Domínguez ÁGuILA, Ramón, "Los accidentes del trabajo. Historia y visión general de su régimen actual", Cuadernos de Extensión Jurídica Universidad de Los Andes, 2011, N²0, pp. 31 y 32; Corte de Apelaciones de Puerto Montt, 4 de julio de 2017, Rol N73-2017; Corte de Apelaciones de San Miguel, 30 de mayo de 2018, Rol No178-2018

${ }^{99}$ Morato, cit. (n. 5), p. 50.

100 Rodríguez, cit. (n. 69), p. 190.

101 El empleador debe exigir a los trabajadores certificación médica de su aptitud para poder desempeñarse en labores calificadas como insalubres o peligrosas, según lo indican los artículos 185 y 186 del Código del Trabajo (V. Dirección del Trabajo, ordinario No2913/050, 20 de julio de 2011), siendo uno de los principales supuestos en que el empleador debe vigilar el estado de salud del trabajador, sin perjuicio de existir otros casos en normas especiales que regulan la vigilancia de la salud en el trabajo.
} 
en la novación de obligaciones. Revisado el Código del Trabajo, tiene lugar: i) en los supuestos del artículo 12, que permiten alterar la naturaleza de los servicios, el sitio en que ellos deban prestarse, el inicio o término de la jornada diaria, todo ello bajo los requisitos que la norma señala; ii) en el caso del artículo 29, extendiendo la jornada ordinaria diaria en supuestos de caso fortuito o fuerza mayor o cuando deban impedirse accidentes o efectuarse arreglos o reparaciones impostergables en las maquinarias o instalaciones; iii) en el supuesto del artículo 403 letra d), en que el empleador puede alterar los turnos $u$ horarios de trabajo durante la huelga en la negociación colectiva reglada, lo que sin duda es una modificación unilateral del contrato de trabajo, por formar tales aspectos parte del mismo, reconociéndose al empleador en virtud de la norma legal modificarlos.

Si bien, según se expuso, se ha reconocido mayoritariamente por la jurisprudencia administrativa, ${ }^{102}$ la jurisprudencia judicial, ${ }^{103}$ la doctrina nacional mayoritaria ${ }^{104} \mathrm{e}$, inclusive, por un sector de la doctrina extranjera, ${ }^{105}$ que el ius variandi es una manifestación del poder de dirección, formando parte de su contenido, lo cierto es que no lo es, existiendo dos diferencias sustanciales entre ambos poderes: su fundamento y contenido. Mientras el fundamento principal del poder de dirección es el contrato individual de trabajo, formando parte de su esencia como expresión de la subordinación, el ius variandi es ajeno al pacto contractual. ${ }^{106} \mathrm{El}$ poder de dirección solamente se puede ejercer una vez celebrado el contrato de trabajo, siendo su presupuesto de ejercicio y su justificación. Por el contrario, el ius variandi

102 Dirección del Trabajo, dictamen N³351/0185, 9 de junio de 1997; Dirección del Trabajo, dictamen $\mathrm{N}^{\circ} 2703 / 0042,19$ de mayo de 2016; Dirección del Trabajo, ordinario $\mathrm{N}^{\circ} 4558,6$ de septiembre de 2016; Dirección del Trabajo, ordinario N5719, 25 de noviembre de 2016; Dirección del Trabajo, ordinario $\mathrm{N}^{\circ} 0345,20$ de enero de 2017; Dirección del Trabajo, ordinario $\mathrm{N}^{\circ} 1504,5$ de abril de 2017; Dirección del Trabajo, ordinario N5030, 26 de octubre de 2017.

${ }^{103}$ Corte de Apelaciones de Copiapó, 17 de octubre de 2016, Rol N82-2016; Corte de Apelaciones de Antofagasta, 12 de mayo de 2017, Rol N51-2017; Corte de Apelaciones de Rancagua, 16 de mayo de 2017, Rol N¹98-2016; Corte de Apelaciones de Iquique, 15 de junio de 2017, Rol N³9-2017; Corte de Apelaciones de Valdivia, 7 de marzo de 2019, Rol N²-2019; Corte de Apelaciones de La Serena, 9 de abril de 2019, Rol N³11-2018.

104 Ugarte, cit. (n. 8), pp. 10-11; Gamonal y Guidi, cit. (n. 8), p. 91.

105 Ferrante, cit. (n. 1), p. 42; Montoya, cit. (n. 2), pp. 135-136; Montoya, cit. (n. 21), pp. 113 y 183-187; Montoya, cit. (n. 69), p. 133 y ss.; Bejarano, cit. (n. 2), pp. 645-646; Garrigues, cit. (n. 69), pp. 40 y 50; MARTínez, cit. (n. 69), pp. 36-37; Alonso y CASAS, cit. (n. 53), pp. 507-508; MarTín, RodrígueZ - SAÑudo y García, cit. (n. 42), pp. 228-229; RodríGuez, cit. (n. 69), p. 190; FABregat, cit. (n. 42), p. 17.

106 Román, cit. (n. 5), pp. 96-99. 
es ajeno al contrato de trabajo, no teniendo fundamento en el mismo, sino en la legislación laboral que le reconoce su procedencia, teniendo vigencia solamente en los casos en que el propio legislador la reconoce su operatividad, de lo contrario, no podrá regir. ${ }^{107}$ De ahí, que para admitir su legitimidad debe buscarse un fundamento legal, debiendo adecuarse su ejercicio a los presupuestos que las normas legales le reconocen, de lo contrario, no se encontrará amparado por el ordenamiento jurídico, encontrándonos ante una apariencia de ius variandi, que es ilegal. Por otra parte, el poder de dirección precisa e integra la prestación laboral, operando dentro del marco fijado por el contrato de trabajo, el que no puede ser modificado por el poder de mando sino respetado y complementado. El mismo actúa dentro del contrato de trabajo y en conformidad al mismo, opera como un poder de conformación, de especificación, siendo una nota distintiva de dicho poder; en cambio, el ius variandi provoca como natural consecuencia la modificación unilateral de ciertos aspectos del pacto laboral como consecuencia de una actuación unilateral del empleador. ${ }^{108}$

El campo de actuación del ius variandi comienza donde termina el del poder directivo, teniendo un carácter accesorio al contrato de trabajo. Por el contrario, el poder directivo se encuentra inescindiblemente unido al contrato de trabajo, no pudiendo desconocerse su vigencia. En fin, se trata de poderes distintos con contenido propio. ${ }^{109}$

(2.4) Facultades administrativas y organizativas laborales y poder de dirección.

La doctrina y jurisprudencia mayoritaria, según se expuso, considera parte integrante del poder de dirección las facultades organizativas laborales, que involucran la determinación de la planilla de trabajadores requerida para ejecutar el trabajo necesario con el objeto de llevar a cabo la actividad empresarial, las modalidades de contrato de trabajo, las remuneraciones y beneficios, la externalización de labores y extinción del contrato de trabajo

\footnotetext{
107 Cester y Mattarolo, cit. (n. 1), pp. 307 y 384.

108 Cester y Mattarolo, cit. (n. 1), p. 384; Cruz, cit. (n. 52), p. 84; Valdés Dal - Re, Fernando, "Movilidad funcional y derechos económicos", en: AA.VV. Estructura salarial, CEOE, Madrid, 1987, p. 110; Rodríguez-PIÑERo Bravo-FERrer, Miguel, "La movilidad del trabajador dentro de la empresa", Documentación Laboral, 1983, N9, p. 31; Poquet, cit. (n. 12), p. 29.

109 Cester y Mattarolo, cit. (n. 1), p. 384; Cruz, cit. (n. 52), p. 84; Valdés, cit. (n. 108), p. 110; Rodríguez -Piñero, cit. (n. 108), p. 31; Poquet, cit. (n. 12), p. 29; Persiani, Mattia; Carinci, Franco, Contratto di Lavoro e Organizzazione. Tomo primo. Contratto e rapporto di lavoro, CEDAM, Milano, 2012, pp. 421-424; LizAma y LizAma, cit. (n. 9) p. 113-115.
} 
por causales distintas a las disciplinarias. ${ }^{110}$ Sin embargo, nuestra posición es que todo lo indicado es expresión de las facultades de administración y organización de que está dotado el empresario, que derivan de la libertad de empresa y el derecho de propiedad, al igual que los poderes del empleador. Sin embargo, la diferencia radica en que tales facultades actúan fuera del contrato de trabajo, no teniendo fundamento en el mismo, no siendo expresión de la subordinación, a diferencia del poder de dirección. Las facultades administrativas y organizativas operan en un momento anterior al contrato de trabajo o bien para extinguirlo, pero no operan al interior del mismo para garantizar su correcto desarrollo. ${ }^{111}$ Las mismas están vinculadas a la general gestión de la empresa, a la organización administrativa ajena a la ejecución del contrato de trabajo. ${ }^{12}$

El hecho que todas las prerrogativas mencionadas sean derechos del empresario, con un mismo fin último, no significa que sean lo mismo, más aun, cuando su fundamento y contenido es diverso. De esta forma, las facultades administrativas y organizativas laborales no forman parte del conjunto de facultades del poder de dirección.

(2.5) Contenido propio del poder de dirección.

Una vez perfeccionado el contrato de trabajo, el poder de dirección comienza a operar en toda su intensidad, atendido que en el origen del mismo se establecen genéricamente los servicios que debe prestar el dependiente, siendo imposible prever en dicho contrato de tracto sucesivo todos los deberes, órdenes e instrucciones que deberá observar el dependiente durante la vigencia de la relación de trabajo. ${ }^{113}$ En virtud del mismo, el empleador determina la forma en que el trabajador ejecutará sus funciones, además de establecer el comportamiento que debe tener al interior de la empresa, siempre respetando los términos del contrato de trabajo, ${ }^{114}$ atendido que su función es especificar el trabajo que debe realizarse e integrar dicho contrato,

\footnotetext{
${ }^{110}$ El despido disciplinario es una sanción impuesta en virtud del poder de dirección. Véase al respecto: FERnÁndez Toledo, Raúl, "El poder disciplinario del empleador: Configuración jurídica de la sanción laboral que puede imponer al trabajador dependiente", Revista de Derecho de la Pontificia Universidad Católica de Valparaíso, 2015, XLIV, pp. 440-444; FERNÁNDEZ, cit. (n. 84), pp. 164-169.

111 Maria, cit. (n. 71) p. 270; Román, cit. (n. 5), pp. 94-95; Morato, cit. (n. 5), p. 38; RodríGUEZPIÑERo, cit. (n. 27), pp. 8-9.

112 Cester y Mattarolo, cit. (n. 1), p. 286.

113 Cester y Mattarolo, cit. (n. 1), p. 290; De Stefano, cit. (n. 14), p. 14.

114 Gamonal y Guidi, cit. (n. 8), p. 90; Lizama y Lizama, cit. (n. 9), p. 113.
} 
pero no modificarlo. La precisión de las labores a desempeñar comprende aspectos cuantitativos y cualitativos de las mismas, comprendiendo la misma, entre otros aspectos, la determinación de: el lugar preciso en que el trabajador desarrollará los servicios; las herramientas de trabajo a utilizar y el modo de operarlas; la forma de ejecutar las labores; con quiénes trabajará el dependiente, lo que es cada vez más relevante, toda vez que una parte significante de las labores en la empresa moderna se realizan en equipos de trabajo. ${ }^{115}$

La intensidad de la órdenes e instrucciones asociadas a la correcta ejecución del crédito laboral varían según la cualificación y jerarquía del dependiente, como también el lugar en que desempeña sus funciones. En efecto, es posible que un trabajador experto en una cierta ciencia o arte reciba escasas órdenes, lo mismo que aquéllos que tengan cargos de jefaturas, tales como gerentes, subgerentes, supervisores, o bien, ejecutan sus labores fuera del lugar de trabajo, sea o no trabajo a domicilio o teletrabajo. Trabajadores respecto de los cuales lo más relevante son las instrucciones iniciales y el resultado de la labor encomendada. De este modo, el poder de dirección es flexible, variando su contenido, intensidad y frecuencia según la naturaleza de los servicios que ejecuta el dependiente y el lugar en que los presta, cuya correcta ejecución es uno de sus objetivos y, quizás, el principal.

También, forman parte del contenido del poder de mando las órdenes que contengan indicaciones sobre trabajadores que ocupan mandos intermedios, tales como supervisores, que marcarán en cada momento los ritmos y condiciones del trabajo a realizar, y ante el cual el dependiente debe eventualmente acreditar el cumplimiento de sus labores, ${ }^{116}$ ejerciendo los mismos en esa labor el poder de dirección. Las disposiciones dirigidas a tutelar la seguridad y salud en los lugares de trabajo, tales como las normas de seguridad que deben observarse en la ejecución de los servicios, la debida utilización de los elementos de seguridad y el desempeño en perfectas condiciones físicas y psíquicas, igualmente, integran el núcleo del poder de dirección. ${ }^{117}$

El trabajador generalmente realiza sus labores en establecimientos de trabajo del empleador junto a otros trabajadores dependientes de la misma

\footnotetext{
115 Morato, cit. (n. 5), p. 51.

116 Morato, cit. (n. 5), p. 45.

117 GutiérRez-Solar CAlvo, Beatriz, El deber de seguridad y salud en el trabajo. Un estudio sobre su naturaleza jurídica, CES, Madrid, 1999, pp. 179 y 182.
} 
empresa o de terceras empresas, lo que es característico de la producción en red, a lo que ha contribuido significativamente la legitimidad de la subcontratación y trabajo de servicios transitorios. Durante su permanencia en la empresa el trabajador debe observar normas de comportamiento, a fin de asegurar la buena marcha de la empresa, y respetar los derechos de los demás trabajadores que se encuentran en el lugar de trabajo. Dentro de estas disposiciones que puede establecer el empleador en virtud del poder directivo se encuentran, entre otras, el deber de abstenerse de usar palabras obscenas en el lugar de trabajo, la obligación de preocuparse del aseo y presentación personal, cuidar los elementos de protección personal y los equipos de trabajo, la prohibición de iniciar riñas o discusiones con compañeros de trabajo, evitar retrasos o faltas de puntualidad, la prohibición de cometer conductas constitutivas de acoso laboral y sexual, no hurtar bienes de la empresa o de propiedad de compañeros de trabajo. En virtud de órdenes de esta naturaleza el empleador persigue evitar comportamientos que puedan entorpecer la convivencia en la empresa y de alguna manera el correcto desempeño de la actividad laboral.

El empresario puede impartir mandatos que originarán deberes de prestación para el dependiente, si están vinculados a la prestación de trabajo misma, o deberes de conducta, si dicen relación más bien con el comportamiento que debe observar el dependiente para con su empleador y compañeros de trabajo; deberes que se complementan mutuamente, logrando que el dependiente actúe debidamente en la empresa, cumpliendo su contrato de trabajo. Pues, el mismo no solamente conlleva ejecutar los servicios encomendados, sino también comportarse debidamente. ${ }^{118}$

Las órdenes que imparte el empresario en base a su poder de dirección pueden ser de tipo general o particular, según se manifiesten en disposiciones organizativas laborales que afectan a un conjunto de trabajadores o a

\footnotetext{
118 Se diferencian en la ejecución del contrato de trabajo los "deberes de prestación” y los "deberes de conducta". Se señala que "los primeros tienen una especial connotación económica, y se traducen en el cumplimiento de prestaciones recíprocas y típicas del contrato de trabajo (el trabajador aporta su fuerza laboral y el empleador paga una remuneración por ello). Los segundos vienen a calificar o descalificar el íntegro cumplimiento de los primeros; presentan un carácter eminentemente ético y dicen relación con el cumplimiento de las obligaciones contraídas dentro del marco de buena fe lo cual, por lo demás, está expresamente reconocido en el artículo 1546 del Código Civil, según cuyo mandato los contratos deben ejecutarse de buena fe", cfr.: LANATA, cit. (n. 8) p. 282; VÁzQUEz VialARD, Antonio, Derecho del Trabajo y Seguridad Social, Astrea, Buenos Aires, 1981, p. 255. En igual sentido: Corte de Apelaciones de Concepción, 13 de octubre de 2000, RDJ, T XCVII, $2^{\mathrm{a}}$ parte, sección $3^{\mathrm{a}}$ (2000), p. 183; Corte de Apelaciones de Temuco, 9 de marzo de 2017, Rol N³19-2016.
} 
una pluralidad de ellos, o bien afectan de forma individual dirigidas a un dependiente en particular. ${ }^{119}$ Las disposiciones generales comúnmente, aunque no necesariamente, se materializan en reglamentos, protocolos, instructivos, procedimientos de trabajo seguro, códigos de conducta. ${ }^{120}$ En cambio, las órdenes e instrucciones particulares comúnmente se llevan a cabo verbalmente.

Como se puede observar, el poder de dirección completa de sustancia el deber de obediencia, mediante disposiciones empresariales que adoptan la forma de mandatos, órdenes o deberes específicos, con el propósito de lograr la ejecución de la prestación laboral debida y mantener la disciplina laboral; disposiciones que deben ser obedecidas por el trabajador de ser impartidas conforme a la normativa que regula el poder de dirección. ${ }^{121}$

\section{INSTRUMENTOS DE EJERCICIO DEL PODER DE DIRECCIÓN}

El empleador no tiene un instrumento único para ejercer el poder directivo, no existiendo una limitación al respecto en el ordenamiento jurídico. Los límites del mismo están más bien vinculados a no exceder el ámbito de actuación del contrato de trabajo, además, de no lesionar los derechos fundamentales de los trabajadores ni adoptar la forma de instrucciones ilegales. De esta forma, cualquier mandato que requiera una conducta activa o pasiva del trabajador para ejecutar los servicios encomendados o cómo comportarse en la empresa es manifestación del ejercicio del poder de mando.

El empresario a través de las más diversas formas de comunicación (personal o escrita), avisos, procedimientos de trabajo, circulares, políticas, códigos de conducta, puede establecerórdenes e instrucciones, generalmente, mediante la forma de obligaciones y prohibiciones, que deben obedecer los trabajadores. Las mismas conllevan ínsito un mandato, ya sea positivo o de abstención, que requieren de los destinatarios un comportamiento determinado.

Las órdenes e instrucciones en que se exterioriza el poder de dirección demandan un determinado comportamiento del trabajador. Las mismas, si bien se emplean como sinónimos, se les ha tratado de diferenciar por

\footnotetext{
119 Poquet, cit. (n. 12), pp. 31-32.

120 Morato, cit. (n. 5), p. 50.

121 Cester y Mattarolo, cit. (n. 1), p. 350; Stewart, cit. (n. 5), pp. 281-282.
} 
el grado de precisión del mandato que conllevan. La orden constituiría el mecanismo a través del cual se expresa el poder directivo, concretando los diversos aspectos de la relación laboral, que específica un determinado comportamiento que el trabajador debe observar, detallándose todos sus contornos. ${ }^{122}$ Las instrucciones, en cambio, conllevan una genérica directriz a la que deben adecuarse los trabajadores en función de los términos en que se desenvuelve la relación de trabajo. ${ }^{123}$

Conforme a lo expuesto, no solamente los reglamentos empresariales son los instrumentos a través de los cuales se materializa el poder de dirección. ${ }^{124}$ Debido a la complejidad de las relaciones laborales, que es cada vez más creciente, atendida la mayor sofisticación de la producción de bienes y servicios, es legítimo que el empleador establezca en el ejercicio del poder directivo obligaciones y prohibiciones en otros cuerpos normativos, tales como los códigos de conducta, protocolos de atención al público, ${ }^{125}$ procedimiento de trabajo o de utilización de maquinaria específica, como también impartir órdenes e instrucciones verbales. El trabajador está obligado a respetar tales mandatos en virtud de su deber de obediencia, incurriendo en una falta laboral si los vulnera.

Ahora bien, la opinión expuesta sobre la amplitud de instrumentos de que dispone el empleador para ejercer su poder directivo no es uniforme, pues la Dirección del Trabajo sin mayor fundamento que el artículo 154 $\mathrm{N}^{\circ} 5$ del Código del Trabajo ha resuelto uniformemente que el "único instrumento idóneo para consignar las obligaciones y prohibiciones impuestas por el empleador a sus trabajadores, en relación con sus labores, permanencia y vida en las dependencias de la respectiva empresa o establecimiento, es el reglamento interno", incluyendo "toda obligación y prohibición dispuesta por el empleador, que diga relación con materias de orden, higiene y seguridad" ${ }^{126}$ Como consecuencia de ello el servicio

${ }^{122}$ Morato, cit. (n. 5), p. 52.

123 Morato, cit. (n. 5), p. 52.

124 Cester y Mattarolo, cit. (n. 1), p. 351; Morato, cit. (n. 5), p.50.

125 Dirección del Trabajo, dictamen N¹689/73, 23 de abril de 2004.

126 Dirección del Trabajo, dictamen N³031/046, 12 de julio de 2010; Dirección del Trabajo, dictamen N³032/047, 12 de julio de 2010; Dirección del Trabajo, dictamen N4936/092, 16 de noviembre de 2010; Dirección del Trabajo, dictamen N³199/032, 18 de julio de 2012; Dirección del Trabajo, dictamen $\mathrm{N}^{\circ} 1835 / 020,3$ de mayo de 2013; Dirección del Trabajo, ordinario $\mathrm{N}^{\circ} 3344,6$ de julio de 2015; Dirección del Trabajo, ordinario N²602, 15 de julio de 2014; Dirección del Trabajo, ordinario $\mathrm{N}^{\circ} 6287,30$ de noviembre de 2015; Dirección del Trabajo, dictamen N²228/38, 22 de abril 2016; Dirección del Trabajo, dictamen N549/12, 31 de enero 2017; Dirección del Trabajo, ordinario N³674, 
público laboral ha resuelto que no son obligatorias para los trabajadores las disposiciones contenidas en instrumentos distintos al reglamento interno o que no forman parte de su contenido, tales como código de conducta, ${ }^{127}$ código de ética, ${ }^{128}$ instructivos, ${ }^{129}$ procedimiento de control de alcohol y drogas, ${ }^{130}$ otros procedimientos y reglamentos distintos al reglamento interno ${ }^{131}$ que contemplan obligaciones y prohibiciones que deben observar los trabajadores.

El artículo $154 \mathrm{~N}^{\circ} 5$ del Código del Trabajo solamente establece un aspecto del contenido mínimo del reglamento interno, disponiendo al efecto: "El reglamento interno deberá contener, a lo menos, las siguientes disposiciones: (...) 5.- las obligaciones y prohibiciones a que estén sujetos los trabajadores", pero no señala en ninguna parte que el reglamento interno es el único instrumento de que dispone el empleador para establecer órdenes, mandatos dirigidos a los trabajadores, ni existe una norma en este sentido en nuestro ordenamiento jurídico. La exigencia que establece el servicio público laboral no es conforme a la normativa del reglamento interno, ni tampoco acorde a la propia esencia del poder de dirección y a las normas constitucionales en que se fundamenta. El empleador puede utilizar cualquier medio para impartir órdenes e instrucciones, siendo el reglamento interno uno de ellos, pero no el único, debiendo respetar sus límites derivados del contrato de trabajo, de las normas reglamentarias, legales y constitucionales, no encontrándose entre ellos, evidentemente, que sólo deba ejercerse el poder de dirección a través del reglamento interno regulado en el Código del Trabajo. Establecer una exigencia de esta naturaleza importa imponer una formalidad no exigida por norma alguna y desconocer el carácter desformalizado del poder de dirección.

10 de agosto de 2017; Dirección del Trabajo, ordinario N4316, 13 de septiembre de 2017; Dirección del Trabajo, ordinario N6237, 22 de diciembre de 2017; Dirección del Trabajo, ordinario N567, 30 de enero de 2018; Dirección del Trabajo, ordinario N¹163, 2 de marzo de 2018.

127 Dirección del Trabajo, dictamen N³199/032, 18 de julio de 2012; Dirección del Trabajo, ordinario $\mathrm{N}^{\circ} 4316,13$ de septiembre de 2017.

${ }^{128}$ Dirección del Trabajo, ordinario N6237, 22 de diciembre de 2017.

129 Dirección del Trabajo, ordinario N567, 30 de enero de 2018.

130 Dirección del Trabajo, dictamen N³032/047, 12 de julio de 2010.

131 Dirección del Trabajo, dictamen N³199/032, 18 de julio de 2012; Dirección del Trabajo, ordinario $\mathrm{N}^{\circ} 2985,6$ de agosto de 2014. 


\section{Los reglamentos internos como integrantes del poder de dirección}

No obstante el intento de algunos autores nacionales por considerar los reglamentos internos como parte de un poder autónomo del empleador, el poder de reglamentación, ${ }^{132}$ al igual como ocurre en la doctrina francesa, ${ }^{133}$ lo cierto es que constituyen una expresión del poder de dirección, ${ }^{134}$ desde que a través de los mismos se impartes órdenes e instrucciones a los trabajadores mediante obligaciones y prohibiciones relacionadas "con sus labores, permanencia y vida en las dependencias de la respectiva empresa o dependencia" (artículo 153 inciso $1^{\circ}$ del Código del Trabajo), que deben obedecer los trabajadores. Lo que es parte del contenido esencial del poder de dirección, no existiendo ningún argumento para excluir el reglamento interno del contenido del mismo, pues ello importaría desconocer la naturaleza del poder de mando. Los reglamentos internos son una forma en que se imparten mandatos a la generalidad de los trabajadores, constituyendo por excelencia "instrumentos de expresión del poder directivo del empresario". ${ }^{135}$

A través del reglamento interno se establecen obligaciones y prohibiciones que deben observar los dependientes. El artículo 153 inciso $1^{\circ}$ del Código del Trabajo establece en lo pertinente: "Las empresas (...) estarán obligadas a confeccionar un reglamento interno de orden, higiene y seguridad que contenga las obligaciones y prohibiciones a que deben sujetarse los trabajadores, en relación con sus labores, permanencia y vida en las dependencias de la respectiva empresa o establecimiento". Por su parte, el artículo $154 \mathrm{~N}^{\circ} 10$ señala "El reglamento interno deberá contener, a lo menos, las siguientes disposiciones: (...) 10.- las obligaciones y prohibiciones a que estén sujetos los trabajadores".

El reglamento interno es elaborado unilateralmente por el empresario,

132 Macchiavello, Guido, Derecho del Trabajo. Teoría jurídica y análisis de las actuales normas chilenas. El contrato individual y la relación de trabajo, Fondo de Cultura Económica, Santiago, 1986, T. I, pp. 239-240; Gamonal, cit. (n. 8), pp. 97-98; Melis Valencia, Christian; Sáez Carlier, Felipe, Derecho del Trabajo. Editorial Jurídica Conosur, Santiago, T. II, 2000, p. 796.

133 Auzero y Dockés, cit. (n. 30), p. 662; Mazeaud, cit. (n. 49), p. 92.

134 Dirección del Trabajo, ordinario $N^{\circ} 11$ de 4 de enero de 2017; Dirección del Trabajo, ordinario N726 de 7 de febrero de 2018; Lizama y Lizama, cit. (n. 9), p. 113, indica que el poder de dirección: "se manifiesta en un conjunto de instrucciones y reglamentos dirigidos a los trabajadores en general". En el mismo sentido un sector de la doctrina comparada: PALOMEQUE Y Álvarez, cit. (n. 42), p. 563; Cester y Mattarolo, cit. (n. 1), p. 351; Morato, cit. (n. 5), p. 50; Santoro Passarelli, Francesco, Nozioni di diritto del lavoro, Jovene, Napoli, 1994, 32a ed., p. 140.

135 Morato, cit. (n. 5), p. 52. 
siendo su confección obligatoria en empresas que ocupan normalmente 10 o más trabajadores (artículo 153 inciso $1^{\circ}$ del Código del Trabajo), y facultativo cuando ocupan menos de esa cantidad de dependientes. ${ }^{136}$ Cualquier trabajador o las organizaciones sindicales solamente pueden impugnar las disposiciones del reglamento que consideren ilegales mediante presentación efectuada ante la autoridad competente, sin perjuicio que dicha autoridad de oficio exija modificar las disposiciones que se estimen ilegales (artículo 153 inciso final del Código del Trabajo), pero no pueden aquéllos realizar por si mismos las modificaciones; facultad solamente reservada al empleador, por ser el titular del poder de dirección.

Conjuntamente con el reglamento interno, se encuentra el reglamento interno de higiene y seguridad en el trabajo, ${ }^{137}$ que deben elaborar las empresas, independientemente del número de trabajadores que ocupen, desde que el artículo 14 del Decreto Supremo $N^{\circ} 40$, del Ministerio del Trabajo y Previsión Social, de 1969, lo establece como obligatorio para "toda empresa o entidad"; 138 reglamento en el cual deben contenerse las obligaciones y prohibiciones que debe observar el trabajador en materia de higiene y seguridad en el trabajo (artículo 67 de la Ley $\mathrm{N}^{\circ} 16.744$ ). El artículo 18 del Decreto Supremo $\mathrm{N}^{\circ} 40$ señala las obligaciones mínimas que deben contener dicho reglamento en seguridad e higiene en el trabajo. Por su parte, el artículo 19 del mismo Decreto Supremo indica las prohibiciones mínimas que debe contener el reglamento, que dicen relación con: "aquellos actos o acciones que no se permitirán al personal por envolver riesgos por sí mismos u otros o para los medios de trabajo". Generalmente el reglamento interno y el reglamento de higiene y seguridad en el trabajo, no obstante ser

\footnotetext{
136 Macchiavello, cit. (n. 132), p. 251.

137 LanATA, cit. (n. 8), p. 43; GAMOnAl y Guidi, cit. (n. 8), p. 100; LANATA, Gabriela, "El acoso laboral y la obligación de seguridad en el trabajo", Revista de Derecho Universidad Austral de Chile, 2018, Vol. XXXI, N¹, p. 122. En el mismo sentido: Dirección del Trabajo, dictamen $\mathrm{N}^{\circ} 136 / 07,8$ de enero de 1996; Dirección del Trabajo, dictamen N970/47, 6 de febrero de 1996: “existen dos reglamentos internos, los cuales tienen distinta naturaleza, a saber, el reglamento regulado en la ley 16.744 que se refiere a la prevención de los accidentes del trabajo y las enfermedades profesionales y el reglamento regulado en el Código del Trabajo el cual se refiere a la mantención del orden, la disciplina y la seguridad dentro de la empresa"; Dirección del Trabajo, dictamen N²701/151, 29 de mayo de 1999; Dirección del Trabajo, dictamen N²680/127, 17 de julio de 2001; Dirección del Trabajo, dictamen $N^{\circ} 4916 / 226$, 21 de diciembre de 2001; Dirección del Trabajo, dictamen N4008/152, 26 de septiembre de 2003.

138 Dirección del Trabajo, dictamen $N^{\circ} 136 / 07,8$ de enero de 1996; Dirección del Trabajo, dictamen N970/47, 6 de febrero de 1996; Dirección del Trabajo, dictamen N²701/151, 29 de mayo de 1999; Dirección del Trabajo, dictamen N4916/226, 21 de diciembre de 2001; Dirección del Trabajo, dictamen N4008/152, 26 de septiembre de 2003.
} 
distintos, se contienen en el mismo documento. ${ }^{139}$

\section{Los códigos de conducta y el poder de dirección}

En la autorregulación de las compañías se ha hecho común la existencia de los llamados "códigos de conducta", los que generalmente son comunes en empresas con estructura compleja y multinacionales. Generalmente los mismos actúan en forma paralela al reglamento interno de orden, higiene y seguridad, operando como complemento del mismo, además, de regular en ocasiones las mismas materias. Los códigos de conducta no tienen una regulación en el ordenamiento jurídico nacional, no existiendo norma jurídica que se refiera a ellos. En términos generales se les conceptualiza como "el documento redactado voluntariamente por la empresa en el que se recoge una declaración expresa de la política, los valores o los principios que han de inspirar el comportamiento de la compañía y sus componentes". ${ }^{140}$

Los códigos de conducta adoptan generalmente este nombre, o bien, códigos de ética, ${ }^{141}$ siendo elaborados unilateralmente por el empleador en el ejercicio de sus facultades directivas, puesto que establecen la reglamentación que deben observar todos los trabajadores, cualquiera sea su jerarquía, tanto en el ámbito interno del lugar de trabajo como en las relaciones con proveedores y trabajadores de terceras empresas. ${ }^{142}$ Los mismos comúnmente no regulan ni precisan la forma de ejecutar la prestación de trabajo, sino que contemplan normas de conducta que deben observar los trabajadores no vinculadas intrínsecamente a la correcta ejecución de los servicios encomendados. Establecen comportamientos éticos, sobre la forma en que deben actuar con otras personas y entidades los dependientes. Ello no impide que con carácter general se establezcan ciertos mandatos que

139 Melis, Christian; SÁEz, Felipe, El contrato individual de trabajo en los dictámenes de la Dirección del Trabajo, LegalPublishing, Santiago, 2009, 2 ed., pp. 625-626: "Es del caso señalar que si bien el Reglamento de Orden, Seguridad e Higiene y el Reglamento de Higiene y Seguridad son instrumentos distintos, que regulan cada uno cuestiones específicas; uno, la ordenación del trabajo y, el otro, las normas sobre seguridad y salud en el centro de trabajo, parece razonable entender, como lo ha hecho la Dirección del Trabajo, que cuando exista la obligación de tener ambos reglamentos, se cumple con dicha obligación al integrarlos en un solo texto que contenga toda la regulación".

${ }^{140}$ Morato, cit. (n. 5), p. 53.

141 Puccio Wulkau, Manuel, Los códigos de ética. Su impacto en el Derecho del Trabajo, Tesis de Magíster en Derecho del Trabajo y Seguridad Social, Universidad de Talca, Chile, 2015, p. 9.

142 Morato, cit. (n. 5), p. 55; Owens, Rosemary; Rilley, Joellen; Murray, Jill, The law of work, Oxford University Press, Melbourne, 2011, 2a edición, p. 77. 
persigan la correcta ejecución de los servicios, que son los menos.

El carácter vinculante de los códigos de conducta ha sido discutido, más aun ante la ausencia de regulación de los mismos en la legislación laboral nacional. ${ }^{143}$ Incluso más, la Dirección del Trabajo ha señalado expresamente que al no estar incorporados al reglamento interno no son obligatorios para el trabajador, quien no tiene el deber de obedecerlos. ${ }^{144}$ Para el servicio público laboral, solamente si se establecen en el reglamento interno son vinculantes. Como se ha expuesto en el punto anterior, el empleador puede impartir mandatos en instrumentos adicionales al reglamento interno, que complementan al mismo, además, de poder regular materias distintas a las que cubre el mismo, en la medida que respeten los límites del contrato de trabajo, las leyes labores y la Carta Fundamental, siendo plenamente procedente los códigos de conducta en nuestro ordenamiento jurídico en forma independiente al reglamento interno.

Para analizar la obligatoriedad del código de conducta es necesario efectuar ciertas precisiones, vinculadas a la forma en que está redactado y su relación con el contrato de trabajo. Las disposiciones contenidas en el mismo que constituyan simples sugerencias, orientaciones o consejos, sobre la actuación que debe tener el dependiente no son obligatorias para el trabajador al no contener una orden, un mandato, que es lo que se imparte a través de las facultades de mando. Por el contrario, si tal instrumento empresarial contempla disposiciones en términos imperativos, requiriendo un determinado comportamiento de los trabajadores, en términos positivos o en forma de prohibición, deben ser obedecidas por los mismos, toda vez que, al ser una manifestación del ejercicio del poder directivo, surge con su establecimiento el deber de obediencia del trabajador. ${ }^{145}$ Deber de obediencia exigible, sea que el trabajador se obligue o no a cumplir el código de conducta a través del contrato de trabajo, atendido que el deber de obediencia es de la esencia del contrato de trabajo como la contracara del poder de mando, imponiendo el mismo al trabajador obedecer las instrucciones impartidas

\footnotetext{
143 Puccio, cit. (n. 141), p. 26.

144 Dirección del Trabajo, dictamen N³199/032 de 18 de julio de 2012; ordinario N4316 de 13 de septiembre de 2017: "el Código de Conducta del Grupo Latam Airlines, como asimismo, las Reglas para la Utilización del Correo Electrónico Corporativo del Grupo Latam Airlines no constituyen disposiciones obligatorias para los trabajadores en sus labores, permanencia y vida en las dependencias de la empresa, susceptibles de ser sancionadas por el empleador en caso de incumplimiento, mientras no estén contenidas en el Reglamento Interno de Orden Higiene y Seguridad de la empresa”; Dirección del Trabajo, ordinario N6237 de 22 de diciembre de 2017.

145 Morato, cit. (n. 5), p. 53.
} 
por el empleador. Por tanto, si el trabajador incumple el código de conducta puede el empleador ejercer su poder de disciplinario, pudiendo inclusive fundar un despido disciplinario en su infracción por parte del trabajador. Es así que la jurisprudencia judicial ha reconocido la validez de tales códigos en juicios donde se impugna el despido disciplinario, considerando una falta laboral la infracción de los mandatos contenidos en el código de conducta. ${ }^{146}$

\section{CONCLUSIONES}

El poder de dirección es uno de los poderes de que está dotado el empleador junto al poder disciplinario, el poder de vigilancia y control y el ius variandi, teniendo cada uno de ellos un contenido propio, a los que deben sumarse las facultades organizativas y administrativas laborales. En el caso del poder directivo está constituido por el conjunto de facultades que permite al empresario especificar los servicios que se obliga a prestar el dependiente en virtud del pacto laboral, además, de establecer las normas que regulan la higiene, seguridad, convivencia y, en general, la disciplina laboral en el lugar de trabajo. De esta forma, no forman parte de dicho poder los otros poderes del empleador ni aspectos propios de las facultades de administrativas y organizativas laborales.

La denominación correcta es la de poder de dirección o poder de mando, no pudiendo calificarse de potestad, por no estar establecido en beneficio exclusivo de un tercero ni originar una simple sujeción del trabajador al empleador. El ejercicio del poder de dirección tiene como contra cara el deber de obediencia del trabajador, cuyo contenido se determina a través del ejercicio del poder de dirección. El mismo no reúne los requisitos que en la teoría del derecho se han exigido para estar en presencia de una potestad. $\mathrm{Su}$ naturaleza jurídica es la de derecho subjetivo potestativo, que no solamente precisa la prestación laboral, sino que también tiene un aspecto normativo, constituyendo obligaciones específicas, especialmente a través de los reglamentos internos, que integran y complementan el contrato de trabajo. Su fundamento y presupuesto de ejercicio es el contrato individual de trabajo, formando parte de la subordinación jurídica; fundamento que es reforzado con las garantías constitucionales de libertad de empresa y

\footnotetext{
${ }^{146}$ Corte de Apelaciones de Valparaíso, 16 de febrero de 2015, Rol N $500-2014$; Corte de Apelaciones de Antofagasta, 21 de noviembre de 2016, Rol N 179-2016; Corte de Apelaciones de Iquique, 19 de enero de 2018, Rol N¹49-2017.
} 
derecho de propiedad reconocidas en la Constitución Política y las normas que regulan los reglamentos empresariales y el contrato de trabajo.

El empleador, en el caso de tener más de 10 trabajadores, debe necesariamente constituir un reglamento interno, como también, constituir un reglamento interno de higiene y seguridad cualquiera sea el número de trabajadores, ello en forma imperativa, constituyendo los mismos expresiones del ejercicio del poder directivo empresarial, siendo vinculantes para los trabajadores desde que comienzan a desempeñarse como dependientes. Pero, además, puede impartir órdenes e instrucciones fundado en dicho poder de cualquier forma, en la medida que respete los derechos fundamentales de los trabajadores, las normas estatales y el contrato de trabajo, inclusive, a través de códigos de conducta, procedimientos de trabajo y otras normas diferentes a los reglamentos internos. Pues, el legislador laboral no ha impuesto ninguna formalidad en el modo de ejercicio el poder de mando, y es sabido que las formalidades son de derecho estricto, debiendo tener una fuente legal, las que no existe en nuestro ordenamiento jurídico para el poder de dirección, salvo en el caso de los reglamentos internos.

\section{BIBLIOGRAFÍA}

\section{A) Doctrina}

Alonso García, Manuel, Curso de Derecho del Trabajo, Ariel, Barcelona, $9^{\mathrm{a}}$ ed., 1985.

Alonso Olea, Manuel; Casas BaAmonde, María Emilia, Derecho del Trabajo, Editorial Civitas S.A., Madrid, 2006, $20^{\mathrm{a}}$ ed. Actualizada.

Alonso Olea, Manuel; Casas Baamonde, María Eugenia, Derecho del Trabajo, Universidad Complutense, Madrid, 1997.

Arriagada, María Beatriz, "Conceptos jurídicos de derechos subjetivos", Eunomía. Revista en Cultura de la Legalidad, oct. 2016 - mar. 2017, $\mathrm{N}^{\circ} 13$.

ArRiagada, María Beatriz, "El concepto Hohfeldiano de derecho subjetivo", Revista de Ciencias Sociales, 2014, $\mathrm{N}^{\circ} 65$.

Auzero, Gilles; Dockés, Emmanuel, Droit du Travail, Dalloz, París, 2016, $30^{\mathrm{a}}$ édition.

Barraco, Enrico; Sitzia, Andrea, Potere di controllo e privacy. Lavoro, riservatezza e nuove tecnología, Wolters Kluwer, Vicenza, 2016.

Bejarano Hernández, Andrés, "Irrenunciabilidad del poder de dirección del empresario y límites convencionales al mismo", Revista Española de Derecho del Trabajo, 2010, $\mathrm{N}^{\circ} 147$. 
Bellavista, Alessandro, Il controllo sui lavoratori, Giappichelli, Torino, 1995.

Carabelli, Umberto, Organizzazione del lavoro e professionalità: una riflessione su contratto di lavoro e post-taylorismo, Centro Studi di Diritto del Lavoro Europeo "Massimo D’Antona”, Catania, 2003.

Carnelutti, Francesco, Teoria generale del Diritto, Foro Italiano, Roma, 1940.

Cester, Carlo; Mattarolo, Maria, Diligenza e obbedienza del prestatore di lavoro. Art. 2014, Giuffrè Editore, Milano, 2007.

Cruz Villalón, Jesús, "Poder de dirección y nuevas estructuras empresariales, en: Escudero, R.(Coord.), El poder de dirección del empresario: nuevas perspectivas, La Ley, Madrid, 2005.

Cruz Villalón, Jesús, Compendio de derecho del trabajo, Tecnos, Madrid, 2010, $3^{\mathrm{a}}$ ed.

Cruz Villalón, Jesús, Las modificaciones de la prestación de trabajo. Madrid, Ministerio del Trabajo y Seguridad Social, 1983.

De Castro y Bravo, Federico, Derecho Civil de España, Instituto de Estudios Políticos, Madrid, 1984.

De Stefano, Valerio, "Negotiating the algorithm: automation, artificial intelligence and labour protection", Employment Working Paper, International Labour Office, 2018, N²46.

Del Valle Villar, José Manuel, "El derecho a la intimidad del trabajador durante la relación de trabajo", Actualidad Laboral, 1991, Vol. III.

Domínguez ÁguILA, Ramón, "Los accidentes del trabajo. Historia y visión general de su régimen actual", Cuadernos de Extensión Jurídica Universidad de Los Andes, 2011, №20.

Fabregat Monfort, Gemma, Nuevas perspectivas del poder de dirección y control del empleador, Editorial Bomarzo, Albacete, 2016.

FERnÁndez Avilés, José Antonio; Rodríguez Rico Roldán, Victoria, "Nuevas tecnologías y control empresarial de la actividad laboral en España", Labour \& Law Issues, 2016, Vol. 2, N¹, 2016.

FERnÁNDez LóPez, María Fernanda, El poder disciplinario en la empresa, Editorial Civitas S.A., Madrid, 1991.

FERnÁNDEZ Toledo, Raúl, “El poder disciplinario del empleador: Configuración jurídica de la sanción laboral que puede imponer al trabajador dependiente", Revista de Derecho Pontificia Universidad Católica de Valparaíso, 2015, XLIV.

FernÁndez Toledo, Raúl, "Precisiones sobre el poder disciplinario del empleador", Revista Chilena de Derecho del Trabajo y de la Seguridad Social, 2015, Vol. 6, N¹1.

Fernández Toledo, Raúl, El poder disciplinario del empleador, Thomson Reuters - La Ley, Santiago, 2016. 
Ferrante, Vincenzo, Direzione e gerarchia nell'impresa (e nel lavoro pubblico privatizzato). Art. 2086, Giuffrè Editore, Milano, 2012.

Gajardo Harboe, María Cristina, "La obligación de seguridad", Revista Chilena de Derecho del Trabajo y de la Seguridad Social, 2014, Vol. 9, №2.

Gamonal Contreras, Sergio; Guidi Moggia, Caterina, Manual del Contrato de Trabajo, LegalPublishing, Santiago, 2012, $3^{\mathrm{a}}$ ed. Revisada y Actualizada.

García de Enterría, Eduardo; Fernández, Tomás - Ramón, Curso de Derecho Administrativo, Civitas - Thomson Reuters, Madrid, 2015, $17^{\text {a }}$ edición, T. I.

García Ninet, José, "Artículo veinte. Dirección y control de la actividad laboral", en: Departamento de Derecho del Trabajo Universidad de Valencia (Coords.), El Estatuto de los Trabajadores. Comentarios a la Ley 8/1980, de 10 de marzo, Edersa, Madrid, 1981.

Garrigues GimÉnez, Amparo, “Obediencia debida y desobediencia del trabajador: su tratamiento en la última jurisprudencia", Tribunal Social, 2000, $\mathrm{N}^{\circ} 120$.

Ghezzi, Georgio; Romagnoli, Umberto, Il rapporto di lavoro, Zanichelli, Bologna, 1987, $2^{\mathrm{a}}$ ed. Actualizada.

GoÑI SEIN, José Luis, El respeto a la esfera privada del trabajador: un estudio sobre los límites del poder de control empresarial, Editorial Civitas S.A., Madrid, 1988.

Gutiérrez - Solar CAlvo, Beatriz, El deber de seguridad y salud en el trabajo. Un estudio sobre su naturaleza jurídica, CES, Madrid, 1999.

Hohfeld, Wesley Newcomb, Conceptos jurídicos fundamentales. (trad. G. Carrió), Distribuciones Fontamara, Ciudad de México, 1995, 3ª ed.

IruReta Uriarte, Pedro, "El núcleo laboral del derecho constitucional a la libertad de empresa", Estudios Constitucionales, 2013, Año 11, №2.

Lanata Fuenzalida, Gabriela, Contrato Individual de Trabajo, LegalPublishing, Santiago, 2010, $4^{\mathrm{a}}$ ed. Actualizada.

LANATA, Gabriela, "El acoso laboral y la obligación de seguridad en el trabajo", Revista de Derecho Universidad Austral de Chile, 2018, Vol. XXXI, N¹.

LARENZ, Karl, Derecho civil. Parte general (Versión castellana de la $3^{\text {a }}$ edición alemana y notas a cargo de M. Izquierdo y Macías-Picavea), Editorial Revista de Derecho Privado, Madrid, 1978.

Lizama Portal, Luis, "Fernández Toledo, Raúl, El poder disciplinario del empleador", Revista Chilena de Derecho del Trabajo y de la Seguridad Social, 2016, Vol. 7, N¹3.

Lizama Portal, Luis; Lizama Castro, Diego, Manual de Derecho Individual del Trabajo, Ediciones DER, Santiago, 2019.

Luque Parra, Manuel, Los límites jurídicos de los poderes empresariales en la relación laboral, Editor J.M. Bosch, Barcelona, 1998.

Macchiavello, Guido, Derecho del Trabajo. Teoría jurídica y análisis de las 
actuales normas chilenas. El contrato individual y la relación de trabajo. Fondo de Cultura Económica, Santiago, 1986, T.20 I.

Maria Mastinu, Enrico, "La procedimentalización sindical del ejercicio de los poderes y prerrogativas del empresario, en: Escudero, R. (Coord.), El poder de dirección del empresario: nuevas perspectivas, La Ley, Madrid, 2005.

MARín Alonso, Inmaculada, El poder de control empresarial sobre el uso del correo electrónico en la empresa, Tirant lo Blanch, Valencia, 2005.

Martín VAlverde, Antonio, "El ordenamiento laboral en la jurisprudencia del Tribunal Supremo". Revista Política Social, 1983, N¹37.

Martín Valverde, Antonio; Rodríguez-SAÑudo Gutiérrez, Fermín; García Murcia, Joaquín, Derecho del Trabajo, Tecnos, Madrid, 1997, sexta edición.

Martínez Rocamora, Luis, Decisiones empresariales y principio de igualdad, Cedecs, Barcelona, 1998.

Mazeaud, Antoine, Droit du travail, Montchrestien, Paris, 2012, $8^{\mathrm{a}}$ édition

Mazzotta, Oronzo, Diritto del Lavoro, Giuffré Editore, Milano, 2011, $4^{\mathrm{a}}$ edizione.

Melis Valencia, Christian; Sáez Carlier, Felipe, Derecho del Trabajo. Tomo II. Editorial Jurídica Conosur, Santiago, 2000.

Melis, Christian; SÁez, Felipe, El contrato individual de trabajo en los dictámenes de la Dirección del Trabajo, LegalPublishing, 2009, 2ª edición.

Monstuschi, Luigi, Potere disciplinare e rapporto di lavoro, Giuffr, Milano, 1973.

Montoya Melgar, Alfredo, "Dirección de la actividad laboral. Art. 20 E.T.", en: Borrajo, E (Dir.), Comentarios a las leyes laborales, Edersa, Madrid, 1985, T. $\mathrm{V}$.

Montoya Melgar, Alfredo, "El poder de dirección del empresario en las estructuras empresariales complejas", Revista del Ministerio del Trabajo y Asuntos Sociales, 2004, N48.

Montoya Melgar, Alfredo, “Libertad de empresa y poder de dirección del empresario en las relaciones laborales" en: Sánchez, C.; González, F. (Coords.), Libertad de empresa y poder de dirección del empresario en las relaciones laborales, Aranzadi - Thomson Reuters, Navarra, 2011.

Montoya Melgar, Alfredo, El poder de dirección del empresario, Instituto de Estudios Políticos, Madrid, 1965.

Morato García, Rosa María, Derecho de resistencia y ejercicio irregular del poder de dirección. Editorial Comares, Granada, 2011.

Owens, Rosemary; Rilley, Joellen; Murray, Jill, The law of work, Oxford University Press, Melbourne, 2011, second edition.

Palomeque López, Manuel Carlos; Álvarez de la Rosa, Manuel, Derecho del Trabajo, Editorial Universitaria Ramón Arces, Madrid, 2011, 20ª edición.

Pera, Giusseppe, Diritto del lavoro, Cedam, Padova, 1984. 
Persiani, Mattia; Carinci, Franco, Contratto di Lavoro e Organizzazione. Tomo primo. Contratto e rapporto di lavoro, CEDAM, Milano, 2012.

PESSI, Roberto, Il potere direttivo dell'imprenditore ed i suoi nuovi limité dopo la legge 29 maggio 1970. N. 300”, Rivista Diritto Lavoro, 1973, N¹.

Poquet CATALÁ, Raquel, El actual poder de dirección y control del empresario, Thomson Reuters - Aranzadi, Pamplona, 2013.

Puccio Wulkau, Manuel, Los códigos de ética. Su impacto en el Derecho del Trabajo, Tesis de Magíster en Derecho del Trabajo y Seguridad Social, Universidad de Talca, Chile, no publicada, 2015.

RIVERo LAMAS, Juan, Limitación de los poderes empresariales y democracia industrial, Universidad de Zaragoza, Zaragoza, 1986.

Rodríguez-PiÑero Bravo-Ferrer, Miguel, "La movilidad del trabajador dentro de la empresa", Documentación Laboral, 1983, N9.

RodrígueZ-Piñero Bravo-Ferrer, Miguel, "Poder de dirección y derecho contractual", en: Escudero, R. (Coord.), El poder de dirección del empresario: nuevas perspectivas, La Ley, Madrid, 2005.

RodríGUEZ InIESTA, Guillermo, "Facultades empresariales de control y vigilancia de la salud 'versus' derecho a la intimidad de los trabajadores", Escudero, R. (Coord.), El poder de dirección del empresario: nuevas perspectivas, La Ley, Madrid, 2005.

Rodríguez Rodríguez, Emma, El poder disciplinario y la negociación colectiva, Editorial Comares, Granada, 2008.

RomÁn de la Torre, María Dolores, Poder de dirección y contrato de trabajo. Ediciones Grapheus, Valladolid, 1992.

Romano, Santi, Fragmentos de un diccionario jurídico (trad. S. Sentís M. y M. Ayerra R.), EJEA, Buenos Aires, 1964.

Ruay SÁEz, Francisco Alberto, "El poder disciplinario del empleador, por Raúl Fernández Toledo. Una reseña", Revista Internacional y Comparada de Relaciones Laborales y Derecho del Empleo, 2017, Vol. 5, №3.

Santoro Passarelli, Francesco, Nozioni di diritto del lavoro, Jovene, Napoli, 1994, $32^{\mathrm{a}}$ ed.

SAVATIER, Jean, "Pouvoir patrimonial et direction des personnes", Droit Social, 1982, $\mathrm{N}^{\circ} 1$.

Stewart, Andrew, Stewart's guide to employment law, The Federation Press, Sydney, 2018, $6^{\text {th }}$ edition.

Stewart, Andrew; Forsyth, Anthony; Irving, Mark; Johnstone, Richard; Mccrystal, Shae, Creighton \& Stewart's labour law, The Federation Press, Sydney, 2016, $6^{\text {th }}$ edition.

Supiot, Alain, Critique du droit du travail, Quadrige, París, 2015, 33 édition.

Terradillos OrmaetXeA, Edurne, El poder disciplinario empresarial. Principios y garantías, Tirant lo Blanch, Valencia, 2004. 
Thayer, William; Novoa, Patricio, Manual de Derecho del Trabajo, Editorial Jurídica de Chile, Santiago, 2010, $5^{\text {a }}$ ed. Actualizada, T. III.

Ugarte Cataldo, José Luis, "El contenido del contrato individual de trabajo", Boletín Oficial de la Dirección del Trabajo, 1996, N94-96.

VALDÉs DAL - RE, Fernando, "Movilidad funcional y derechos económicos", en: AA.VV. Estructura salarial, CEOE, Madrid, 1987.

VALDÉs DAL - RE, Fernando, "Poderes del empresario y derechos de la persona del trabajador", en: Aparicio, J.; Baylos, A. (Coords.), Autoridad y democracia en la empresa, Trotta, Madrid, 1992.

Vallebona, Antonio, Instituzioni di Diritto del Lavoro. II. Il rapporto di Lavoro, CEDAM, Milano, 2012, 8 a edizione.

VARCIN, Francoise, "Le pouvoir patronal de direction", Tesis de Doctorado en Derecho Université Lumiére - Lyon II, Francia, no publicada, 2000.

VÁsquez Vialard, Antonio, Derecho del Trabajo y Seguridad Social, Astrea, Buenos Aires, 1981.

Veneziani, Bruno, I controlli dell'impeditore e i contratti di lavoro, Cacucci, Bari, 1975.

\section{B) Jurisprudencia citada}

Corte de Apelaciones de Antofagasta, 12 de mayo de 2017, Rol N51 2017. 2016.

Corte de Apelaciones de Antofagasta, 14 de octubre de 2016, Rol N 185 -

Corte de Apelaciones de Antofagasta, 21 de noviembre de 2016, Rol N 179 $-2016$.

Corte de Apelaciones de Concepción, 13 de octubre de 2000, RDJ, T XCVII, $2^{\mathrm{a}}$ parte, sección $3^{\mathrm{a}}$ (2000), p. 183.

Corte de Apelaciones de Copiapó, 17 de octubre de 2016, Rol N82 - 2016. Corte de Apelaciones de Iquique, 15 de junio de 2017, Rol №39 - 2017.

Corte de Apelaciones de Iquique, 19 de enero de 2018, Rol N¹49 - 2017.

Corte de Apelaciones de La Serena, 9 de abril de 2019, Rol N³11 - 2018.

Corte de Apelaciones de Puerto Montt, 4 de julio de 2017, Rol No73 - 2017.

Corte de Apelaciones de Rancagua, 16 de mayo de 2017, Rol N¹98 - 2016. 2018.

Corte de Apelaciones de San Miguel, 30 de mayo de 2018, Rol No178 -

Corte de Apelaciones de Santiago, 29 de marzo de 2019, Rol N²555 - 2018.

Corte de Apelaciones de Santiago, 9 de febrero de 2018, Rol N²134 - 2017.

Corte de Apelaciones de Temuco, 9 de marzo de 2017, Rol N`319 - 2016.

Corte de Apelaciones de Valdivia, 7 de marzo de 2019, Rol N² - 2019. 
Corte de Apelaciones de Valparaíso, 16 de febrero de 2015, Rol №500 2014

Corte de Apelaciones de Valparaíso, 29 de mayo de 2018, Rol N²37 2018

Corte Suprema, 4 de septiembre de 2017, Rol N¹5.403 - 2017.

Dirección del Trabajo, 08 de enero de 1996, Dictamen N¹36/07.

Dirección del Trabajo, 23 de abril de 2004, Dictamen $N^{\circ} 1689 / 73$.

Dirección del Trabajo, 03 de mayo de 2013, Dictamen $N^{\circ} 1835 / 020$.

Dirección del Trabajo, 17 de enero de 2002, Dictamen N¹95/8.

Dirección del Trabajo, 17 de abril de 1987, Dictamen N²084/104.

Dirección del Trabajo, 06 de junio de 2014, Dictamen N²127/020.

Dirección del Trabajo, 05 de junio de 2009, Dictamen N²210/035.

Dirección del Trabajo, 22 de abril 2016, Dictamen N²228/38.

Dirección del Trabajo, 2 de junio de 2005, Dictamen N²376/65.

Dirección del Trabajo, 17 de julio de 2001, Dictamen N²680/127.

Dirección del Trabajo, 29 de mayo de 1999, Dictamen N²701/151.

Dirección del Trabajo, 19 de mayo de 2016, Dictamen N²703/0042.

Dirección del Trabajo, 30 de agosto de 2002, Dictamen N²856/162.

Dirección del Trabajo, 11 de enero de 1996, Dictamen N²87/14.

Dirección del Trabajo, 22 de julio de 2003, Dictamen N²875/72.

Dirección del Trabajo, 09 de junio de 1997, Dictamen N³351/0185.

Dirección del Trabajo, 20 de agosto de 2003, Dictamen N³363/103.

Dirección del Trabajo, 03 de septiembre de 2014, Dictamen N³406/054.

Dirección del Trabajo, 20 de agosto de 2008, Dictamen N³441/072.

Dirección del Trabajo, 06 de julio de 2016, Dictamen N³537/63.

Dirección del Trabajo, 02 de octubre de 2001, Dictamen N³659/180.

Dirección del Trabajo, 31 de agosto de 2004, Dictamen N³992/160.

Dirección del Trabajo, 26 de septiembre de 2003, Dictamen N4008/152.

Dirección del Trabajo, 04 de agosto de 1997, Dictamen N$^{\circ} 4589 / 260$.

Dirección del Trabajo, 21 de diciembre de 2001, Dictamen N4916/226.

Dirección del Trabajo, 16 de noviembre de 2010, Dictamen N4936/092.

Dirección del Trabajo, 16 de diciembre de 2014, Dictamen N5073/082.

Dirección del Trabajo, 31 de enero 2017, Dictamen N549/12.

Dirección del Trabajo, 30 de noviembre de 1999, Dictamen N5845/365.

Dirección del Trabajo, 21 de enero de 1991, Dictamen N626/13.

Dirección del Trabajo, 11 de diciembre de 1995, Dictamen N8005/323.

Dirección del Trabajo, 06 de febrero de 1996, Dictamen N970/47.

Dirección del Trabajo, 08 de febrero de 1995, Dictamen Nº1043/42.

Dirección del Trabajo, 19 de julio de 2002, Dictamen N²328/130.

Dirección del Trabajo, 30 de agosto de 2002, Dictamen No2852/158.

Dirección del Trabajo, 12 de julio de 2010, Dictamen No3031/046. 
Dirección del Trabajo, 12 de julio de 2010, Dictamen N³032/047.

Dirección del Trabajo, 18 de julio de 2012, Dictamen N³199/032.

Dirección del Trabajo, 16 de octubre de 2002, Dictamen No3276/173.

Dirección del Trabajo, 20 de enero de 2017, Ordinario $\mathrm{N}^{\circ} 0345$.

Dirección del Trabajo, 04 de enero de 2017, Ordinario $\mathrm{N}^{\circ} 11$.

Dirección del Trabajo, 2 de marzo de 2018, Ordinario $N^{\circ} 1163$.

Dirección del Trabajo, 04 de marzo de 2016, Ordinario N 1265.

Dirección del Trabajo, 05 de abril de 2017, Ordinario N 1504.

Dirección del Trabajo, 29 de mayo de 2017, Ordinario №2292.

Dirección del Trabajo, 06 de agosto de 2014, Ordinario Nº2985.

Dirección del Trabajo, 09 de julio de 2018, Ordinario N³125.

Dirección del Trabajo, 06 de julio de 2015, Ordinario N³344.

Dirección del Trabajo, 10 de agosto de 2017, Ordinario N³674.

Dirección del Trabajo, 13 de julio de 2018, Ordinario N³739.

Dirección del Trabajo, 04 de agosto de 2016, Ordinario N 4064.

Dirección del Trabajo, 13 de septiembre de 2017, Ordinario N4316.

Dirección del Trabajo, 23 de agosto de 2018, Ordinario $\mathrm{N}^{\circ} 4457$.

Dirección del Trabajo, 06 de septiembre de 2016, Ordinario N4558.

Dirección del Trabajo, 04 de octubre de 2017, Ordinario N4606.

Dirección del Trabajo, 26 de octubre de 2017, Ordinario N5030.

Dirección del Trabajo, 07 de octubre de 2015, Ordinario №5101.

Dirección del Trabajo, 08 de noviembre de 2016, Ordinario N5417.

Dirección del Trabajo, 30 de enero de 2018, Ordinario N567.

Dirección del Trabajo, 25 de noviembre de 2016, Ordinario N5719.

Dirección del Trabajo, 22 de diciembre de 2017, Ordinario №6237.

Dirección del Trabajo, 30 de noviembre de 2015, Ordinario $\mathrm{N}^{\circ} 6287$.

Dirección del Trabajo, 2 de diciembre de 2015, Ordinario $\mathrm{N}^{\circ} 6342$.

Dirección del Trabajo, 10 de diciembre de 2015, Ordinario №6463.

Dirección del Trabajo, 07 de febrero de 2018, Ordinario N²726.

Dirección del Trabajo, 16 de febrero de 2017, Ordinario Nº00.

Dirección del Trabajo, 20 de marzo de 2013, Ordinario Nº1165.

Dirección del Trabajo, 15 de julio de 2014, Ordinario No2602.

Dirección del Trabajo, 20 de julio de 2011, Ordinario N²913/050.

Juzgado de Letras y del Trabajo de Victoria, 11 de octubre de 2018, RIT O-7-2018.

Juzgado de Letras y del Trabajo de Victoria, 11 de octubre de 2018, RIT O-7-2018.

1er Juzgado de Letras del Trabajo de Santiago, 11 de enero de 2017, RIT O-4982-2016. 
C) Fuentes legales citadas

Código Civil, D.F.L. $\mathrm{N}^{\circ} 1$ del Ministerio del Trabajo y Previsión Social, 2000 .

Código del Trabajo, D.F.L. Nº1 del Ministerio de Justicia, 2002.

Decreto Supremo N40 del Ministerio del Trabajo y Previsión Social, 1969. Ley $N^{\circ} 16.744,1968$. 